\title{
Combining Multiscale Experimental and Computational Systems Pharmacological Approaches to Overcome Resistance to HER2-targeted Therapy in Breast Cancer\$
}

\author{
Tanaya R. Vaidya, ${ }^{1}$ Anusha Ande, ${ }^{1}$ and Sihem Ait-Oudhia \\ Center for Pharmacometrics and Systems Pharmacology, Department of Pharmaceutics, College of Pharmacy, University of \\ Florida, Orlando, Florida
}

Received December 10, 2018; accepted March 15, 2019

\begin{abstract}
The emergence of human epidermal growth factor receptor type-2 (HER2) therapy resistance in HER2-positive (HER2+) breast cancer $(\mathrm{BC})$ poses a major clinical challenge. The primary mechanisms of resistance include aberrant activation of the HER2 and phosphatidylinositol 3-kinase/mammalian target of rapamycin/AKT8 virus oncogene cellular homolog (PI3K/Akt/ mTOR) pathways. The existence of feedback loops in this pathway may engender resistance to targeted therapies such as everolimus, an mTOR inhibitor, resulting in a more aggressive form of refractory HER2 + BC. Here, we hypothesize that a triple and sequential combination therapy of paclitaxel, a potent cytotoxic agent, before concomitant administration of dasatinib, a SRC proto-oncogene nonreceptor tyrosine kinase (Src) family kinase inhibitor, with everolimus, restores sensitivity to treatment in refractory HER2+ BC. This was assessed by a combination of experimental and computational approaches. Quantitative
\end{abstract}

systems pharmacological (QSP), pharmacokinetics (PK), and pharmacodynamics (PD) studies were conducted in static and three-dimensional and dynamic (3DD) cell culture systems using a HER2 + cell line resistant to HER2 therapy, JIMT-1. The dynamic responses in cellular viability and key signaling proteins in the HER2 and PI3K/Akt/mTOR pathways were measured upon treatments with single drugs, combinations, and appropriate controls. A QSP-PK/PD model was developed and used to optimize the sequence and interdose interval of the three agents in the combination. The proposed sequential combination therapy demonstrated strong cytotoxic effects in JIMT-1 cells, and our models predicted the usefulness of this combination over prolonged durations in the 3DD setting. Our combined experimental and QSP-PK/PD modeling approach may serve as a useful screening tool in predicting clinical efficacy of combination therapies in oncology. Nonetheless, further in vivo human xenograft tumor studies are warranted.

\section{Introduction}

Human epidermal growth factor receptor type-2 positive breast cancer (HER2+ BC) is characterized by an overexpression of the HER2 receptor on the cell surface in approximately $25 \%$ of all breast cancers. It has been associated with poor prognosis, a higher incidence of metastases, and a shorter overall survival as compared with most other BC subtypes (Loibl and Gianni, 2017). HER2-targeted therapies such as trastuzumab (Herceptin) and lapatinib (TYKERB) have demonstrated improved clinical outcomes in HER2+ metastatic $\mathrm{BC}$, but innate and/or acquired treatment resistance may occur (Yarden, 2001; Pohlmann et al., 2009; Singh et al., 2014; Zhang et al., 2017). Resistance to HER2 therapy in HER2+ BC patients has become an important clinical unmet medical need,

\footnotetext{
${ }^{1}$ T.R.V. and A.A. contributed equally to this work.

https://doi.org/10.1124/jpet.118.255752.

S This article has supplemental material available at jpet.aspetjournals.org.
}

motivating the search for alternative treatment approaches to overcome resistance and prolong patients' survival. Here, we propose to resensitize and/or combat a difficult-to-treat BC that is refractory to HER2 therapy via a novel combination therapy comprising three agents with distinct but complementary mechanisms of action, including everolimus, dasatinib, and paclitaxel.

Everolimus is a small molecule inhibitor of the mammalian target of rapamycin complex 1 (mTORC1) protein complex in the phosphatidylinositol 3-kinase/AKT8 virus oncogene cellular homolog/mammalian target of rapamycin (PI3K/Akt/ mTOR) pathway (Houghton, 2010), which is aberrantly activated in HER2-positive cancers (Wilks, 2015). Everolimus exerts its antitumor effects through mTORC1-mediated dephosphorylation of ribosomal protein S6 kinase-1 (S6K1) and eukaryotic translation initiation factor 4E-binding protein 1 (4E-BP1), causing signal blockade in the PI3K/Akt/ mTOR pathway and inhibition of cellular proliferation (O'Brien et al., 2014). In contrast, the inhibition of mTORC1 releases a feedback activation loop mediated by insulin-like growth

ABBREVIATIONS: 2D, two-dimensional; 3DD, three-dimensional and dynamic; Akt, AKT8 virus oncogene cellular homolog; BC, breast cancer; CCK-8, cell counting kit-8; DE, dasatinib + everolimus simultaneous treatment; HER2, human epidermal growth factor receptor type-2; IGF-1R, insulin-like growth factor receptor type-1; IRS-1, insulin receptor substrate-1; $\mathrm{m}_{\text {TOR }}$, mammalian target of rapamycin; mTORC1, mammalian target of rapamycin complex 1; PD, pharmacodynamics; $\mathrm{P}(\mathrm{DE})$, paclitaxel followed by dasatinib + everolimus sequential treatment; pAkt, phosphorylated Akt; PDE, paclitaxel + dasatinib + everolimus treatment; PI3K, phosphatidylinositol 3-kinase; PK, pharmacokinetic; pmTOR, phosphorylated mTOR; pSrc, phosphorylated Src; QSP, quantitative systems pharmacology; S6K1, ribosomal protein S6 kinase-1; SFKs, Src family kinases; Src, SRC proto-oncogene nonreceptor tyrosine kinase; TTR, time to tumor regrowth. 
factor receptor type-1 (IGF-1R) and the insulin receptor, which results in the activation of insulin receptor substrate-1 (IRS-1) and in turn activates Akt located upstream of mTORC1 (O'Reilly et al., 2006).

Thus, a second agent targeting a signaling protein upstream of Akt is needed to counterregulate this feedback activation loop (Yori et al., 2014). One such targeted small molecule agent is dasatinib (Araujo and Logothetis, 2010). Dasatinib is a multikinase inhibitor of SRC proto-oncogene nonreceptor tyrosine kinase (Src), a proto-oncogene from the Src family kinases (SFKs), located upstream of Akt. It is responsible for regulating multiple cellular growth pathways via the signaling proteins Akt, mitogen-activated protein kinase (MAPK), and signal transducer and activator of transcription 3 (STAT3) (Chang and Wang, 2013). Its overactivation has been implicated in HER2+ BC cells' resistance to trastuzumab and lapatinib (De Luca et al., 2014; Jin et al., 2017). The dual inhibition of $m$ TOR and SFKs in a mouse model of HER2+ BC efficaciously caused tumor regression via prevention of the Akt feedback activation loop, thus supporting the hypothesis that combination of everolimus with dasatinib may be successful at combating treatment resistance in HER2+ BC (Dehm and Bonham, 2004; Yori et al., 2014).

To further enhance the tumor inhibitory effects of everolimus and dasatinib, we selected paclitaxel as a standard cytotoxic agent. Paclitaxel cell-killing results from microtubule stabilization, leading to mitotic arrest and subsequently cancer cell death (Horwitz, 1994). In ovarian granulosa tumor cells, paclitaxel in combination with dasatinib or mTOR inhibitors showed a synergistic growth inhibitory effect (Haltia et al., 2017). Thus, the potent cytotoxic activity of paclitaxel mediated by the activation of apoptotic pathways increases the likelihood of achieving synergistic tumor cell-killing when used in combination with the proposed targeted cytostatic agents in refractory HER2+ BC.

In the present work, we sought to evaluate the efficacy of our proposed triple combination therapy. We conducted in vitro cell culture studies in two-dimensional (2D) static and threedimensional dynamic (3DD) settings using JIMT-1, a HER2+ BC cell line resistant to trastuzumab and lapatinib (Köninki et al., 2010). Concentration-response, time-dependent cell-killing, and activity of key signaling proteins were examined upon exposure of JIMT-1 cells to single and combination therapies. A pharmacokinetic and pharmacodynamic (PK/PD) study was conducted using a 3DD cell culture system (Ho et al., 2004; Toriniwa and Komiya, 2007; Ande et al., 2018).

A quantitative systems pharmacology (QSP) PK/PD model was developed, and it characterized well all the observed data. The developed QSP-PK/PD model served as an in silico tool for simulations of optimized dosing regimens and inter-dose intervals of the three agents that best resensitize (or overcome) resistance in HER2+ BC. Our strategy of combining experimental and computational modalities is promising and may enable predictions of the clinical efficacy of the proposed triple combination as well as other therapeutic strategies in oncology.

\section{Material and Methods}

\section{Drugs and Reagents}

Paclitaxel, everolimus, and dasatinib were purchased from Selleck Chemicals (Houston, TX). The JIMT-1 cell line was purchased from the American Type Culture Collection (ATCC, Manassas, VA). Cell culture reagents including Dulbecco's modified Eagle's medium (DMEM), sodium bicarbonate solution, and nonessential amino acids solution were purchased from Corning (Tewksbury, MA). FBS and cell counting kit-8 (CCK-8) were purchased from Sigma-Aldrich (St. Louis, MO). The bicinchoninic acid (BCA) protein assay kit and protease inhibitor cocktail were obtained from Thermo Fisher Scientific (Waltham, MA). Crystal violet nuclear dye and the 3DD cell culture (BelloCell) system apparatus were purchased from Chemglass Life Sciences (Vineland, NJ). Caspase-3 colorimetric assay kit for assessing caspase-3 activity was purchased from Abcam (Cambridge, MA). The radioimmunoprecipitation assay (RIPA) buffer was obtained from Boston BioProducts, (Ashland, MA). Phosphorylated Akt (pAkt), Src (pSrc), and mTOR (pmTOR) protein assay kits were purchased from EMD Millipore (Billercia, MA). Quantitative protein assays were conducted using the MAGPIX multiplexing instrument from Luminex Corporation (Austin, TX). Colorimetric assays for cell viability and caspase-3 activity were performed using a microplate spectrophotometer (BioTek Instruments, Winooski, VT).

\section{Two-Dimensional (2D) or Static Cell Culture Experiments}

Concentration-response relationships were examined in vitro after exposure of JIMT-1 cells to paclitaxel, everolimus, and dasatinib, as described previously elsewhere (Ande et al., 2018). Caspase-3 activity in JIMT-1 cells was measured over a time course of $0,6,12,24,48$, and 72 hours after exposure to $50 \mathrm{nM}$ paclitaxel, everolimus, and dasatinib as single agents and combinations by use of a colorimetric caspase-3 assay kit (Abcam), as per the manufacturer's instructions. Total and phosphorylated Src, Akt, and mTOR proteins were measured over a period of $0,1,3,6,12,24$, and 48 hours after exposure of JIMT-1 cells to single agents and combinations of agents by use of protein assay kits from EMD Millipore, as per the manufacturer's protocols. Cell viability over a time course of $0,24,48,72$, and 96 hours was measured by use of the CCK- 8 kit (Sigma-Aldrich) after exposure of JIMT-1 cells to the single agents as well as combinations.

\section{Three-Dimensional and Dynamic (3DD) Cell Culture Experiments}

A PK/PD study was conducted in a novel 3DD cell culture system (BelloCell; Supplemental Fig. 1) by exposing JIMT-1 cells to a triple combination of paclitaxel followed by sequential administration of dasatinib plus everolimus under dynamic conditions, as described previously elsewhere (Ande et al., 2018). Briefly, the 3DD system is an oscillating bioreactor that allows for high-population-density culture of cells over long periods of time (15-20 days). It is a fluid flow system that allows drug concentrations to be varied over time to mimic animal/human PK. Additionally, PD biomarkers can be sampled and measured without perturbing the system as such (Ho et al., 2004; Toriniwa and Komiya, 2007).

In the present study, paclitaxel was administered as a 3-hour continuous infusion at a rate of $3.75 \mu \mathrm{g} /$ minute to achieve a peak concentration of approximately $50 \mathrm{nM}$, based on a preliminary pilot study. On the following day, everolimus and dasatinib were administered into the system simultaneously with a constant concentration maintained at $50 \mathrm{nM}$ for 72 hours, followed by a washout phase. PK samples were collected over a period of 96 hours starting from day 0 for measurement of paclitaxel concentrations in the system. Paclitaxel concentrations were quantified using high-pressure liquid chromatography-tandem mass spectrometry (LC-MS/MS). JIMT-1 cell viability was assessed every 24-48 hours throughout the duration of the study using a crystal violet nuclear dye counting kit (Chemglass Life Sciences).

\section{QSP Model for Protein and Cellular Responses from the 2D Cell Culture Setting}

Key proteins in the signaling pathway of HER2-therapy resistant $\mathrm{BC}$ cells were identified, and their activity was measured in vitro over 
a time course, upon exposure of JIMT-1 cells to paclitaxel, dasatinib, and everolimus as single agents and combinations. Model building was performed by characterization of protein dynamics and cellular responses after perturbation of protein activity in response to 1) the single agents paclitaxel (P), dasatinib (D), and everolimus (E); 2) dual combination therapy of dasatinib + everolimus (DE); and 3) triple combination therapy of paclitaxel + dasatinib + everolimus (PDE, simultaneous) and paclitaxel followed by dasatinib + everolimus $(\mathrm{P}(\mathrm{DE})$, sequential), as depicted in Fig. 1. All measured proteins were characterized using turnover rate constants (system parameters) across all treatment arms, and protein perturbations due to various treatment regimens were characterized using transit compartment models with inhibition or stimulation coefficients (Sun and Jusko, 1998; Lobo and Balthasar, 2002), as applicable (drug-related parameters).

All mathematical modeling was performed using Monolix software version 2016R1 (Lixoft SAS, 2016).

\section{Single Agents.}

Paclitaxel. Model development for paclitaxel was initiated with pAkt being inhibited through the use of a precursor pool indirect response model (Sharma et al., 1998). Inhibition of the PI3K/Akt pathway is implicated in paclitaxel-mediated cell death in BC cells via activation of c-Jun $\mathrm{N}$-terminal kinases (JNK), leading to activation of the apoptotic machinery (Sunters et al., 2006). Moreover, aberrant activation of this pathway is characteristic of HER2-therapy resistant $\mathrm{BC}$ cells, making it a key pathway for examination of protein activity perturbations.

Inhibition of Akt activity leads to the inhibition of its downstream protein mTOR via dephosphorylation, which in turn causes the inhibition of cell proliferation through inhibition of ribosomal S6K, as described previously. Inhibition of Akt activity was accounted for in the model through the inhibition of a hypothetical compartment, Akt $_{\text {Ic }}$, upstream of Akt, which phosphorylates Akt (Chudasama et al., 2015; Vaidya et al., 2018). Akt protein activity, however, returns to its baseline after approximately 6 hours (Fig. 2). Therefore, a precursor pool based indirect response model was used to capture this trend, as depicted in the following equations:

$$
\begin{aligned}
& \frac{d\left(\mathrm{Akt}_{\mathrm{Ic}}\right)}{d t}=K_{\mathrm{inh}} \cdot\left(1-\left(C_{\mathrm{P}} \cdot I_{\mathrm{p}}\right)\right)-K_{\mathrm{inh}} \cdot \mathrm{Akt}_{\mathrm{Ic}} ; \mathrm{Akt}_{\mathrm{Ic}}(0)=1 \\
& \frac{d\left(\mathrm{pre}_{\mathrm{pAkt}}\right)}{d t}=K_{\mathrm{Akt}}-K_{\mathrm{Akt}} \cdot \mathrm{Akt}_{\mathrm{Ic}} \cdot \operatorname{pre}_{\mathrm{pAkt}} ; \operatorname{pre}_{\mathrm{pAkt}}(0)=1 \\
& \frac{d p \mathrm{Akt}}{d t}=K_{\mathrm{Akt}} \cdot \mathrm{Akt}_{\mathrm{Ic}} \cdot \mathrm{pre}_{\mathrm{pAkt}}-K_{\mathrm{Akt}} \cdot \mathrm{pAkt} ; \operatorname{pAkt}(0)=1
\end{aligned}
$$

where, pre pAkt $_{\text {and }}$ pAkt represent the precursor pool compartment and pAkt compartment, $K_{\mathrm{inh}}$ is the turnover rate constant for the inhibitory compartment $\mathrm{Akt}_{\mathrm{Ic}}$, and $K_{\mathrm{Akt}}$ is the turnover rate constant for the precursor pool and Akt protein. $C_{\mathrm{P}}$ represents the paclitaxel concentration ( $50 \mathrm{nM}$ ), and $I_{\mathrm{P}}$ represents the coefficient for its inhibitory effect on cancer cells. All protein dynamic data were normalized to the no-treatment control arm. Therefore, homeostasis was maintained for the control protein dynamic data at a level of 1 unit under unperturbed conditions to satisfy the law of mass balance. The initial conditions for all protein compartments were set at 1 .

Further, the inhibitory effect of pAkt on pmTOR was described through the following equations. Two transit compartments were able to adequately describe the delay in signaling between pAkt and

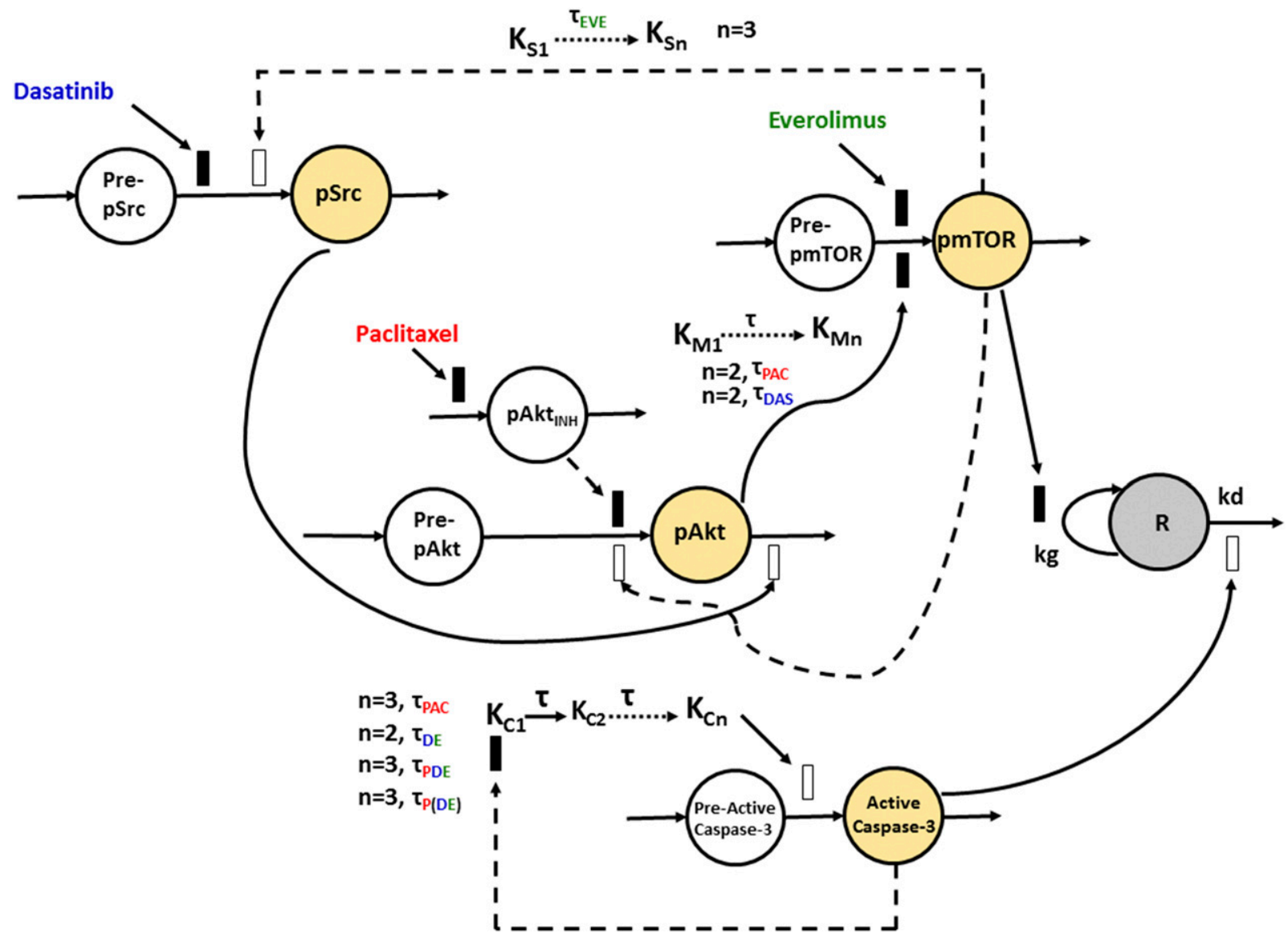

Fig. 1. Model structure for key protein signaling pathways affected by paclitaxel, dasatinib, and everolimus as single agents and combinations in JIMT1 breast cancer cells resistant to HER2-targeted therapy. Yellow compartments represent measured protein activity. Gray compartment represents measured cell viability. Black solid rectangles represent inhibition processes, and black open rectangles represent stimulation processes. Dashed arrows represent feedback loops. 


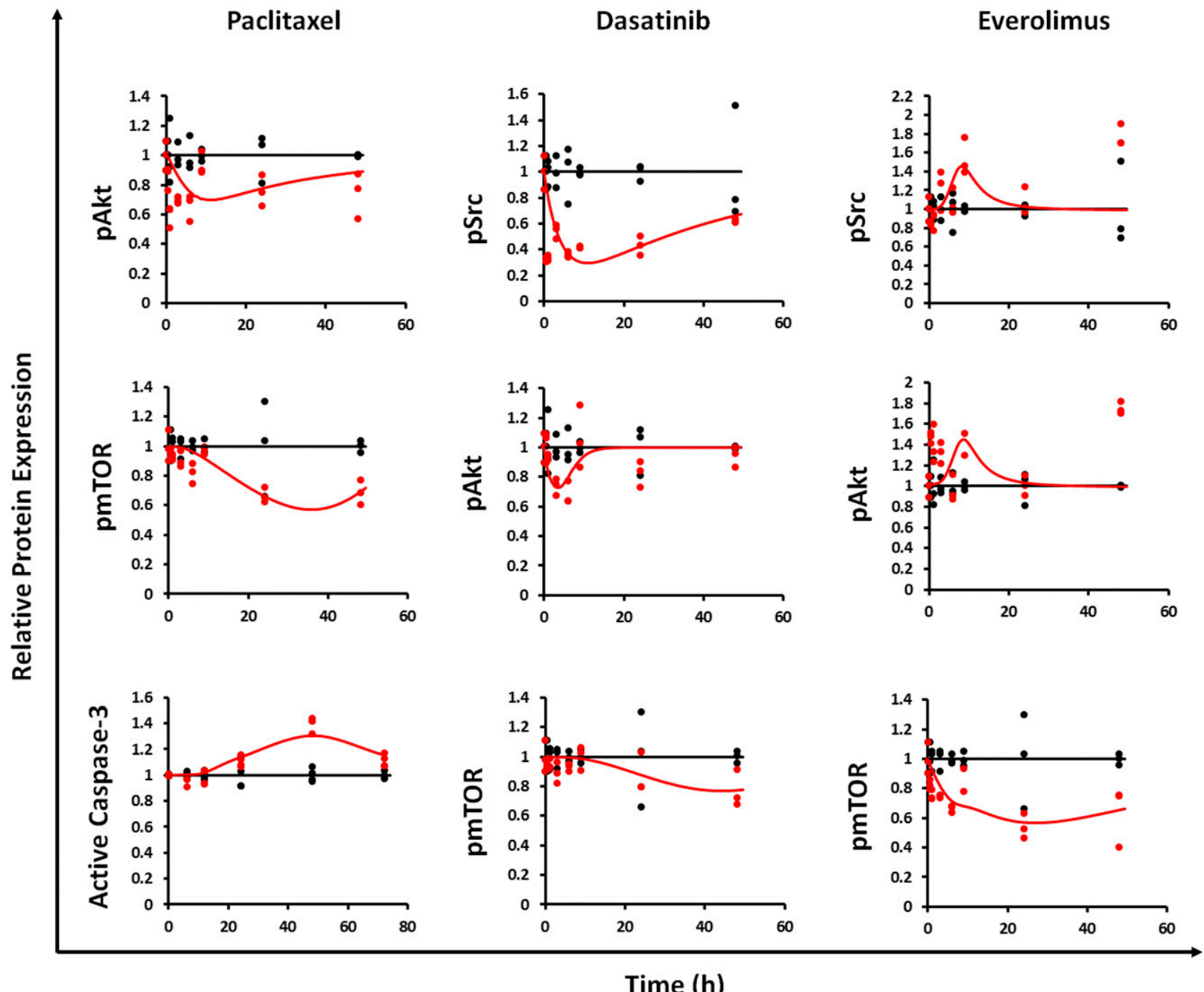

Fig. 2. Time course of cellular protein dynamics after continuous exposure of JIMT-1 cells to the single agents paclitaxel (50 nM), dasatinib (50 $\mathrm{nM}$ ), and everolimus $(50 \mathrm{nM})$ for 72 hours. Relative protein expression profiles are shown for pSrc (for dasatinib and everolimus), pAkt and pmTOR for all three agents, and Caspase-3 activity for paclitaxel. Black circles represent observed data under control conditions, and red circles represent observed data under treatment conditions. Solid lines represent model fittings.

pmTOR proteins (Sun and Jusko, 1998; Lobo and Balthasar, 2002) as follows:

$$
\begin{gathered}
\frac{d K_{\mathrm{M} 1}}{d t}=\left(\frac{1}{\tau_{\mathrm{MP}}}\right) \cdot\left(\left(\mathrm{pAkt}^{S 1_{\mathrm{P}}}\right)-K_{\mathrm{M} 1}\right) ; K_{\mathrm{M} 1}(0)=1 \\
\frac{d K_{\mathrm{M} 2}}{d t}=\left(\frac{1}{\tau_{\mathrm{MP}}}\right) \cdot\left(K_{\mathrm{M} 1}-K_{\mathrm{M} 2}\right) ; K_{\mathrm{M} 2}(0)=1 \\
\frac{d\left(\mathrm{pre}_{\mathrm{pmTOR}}\right)}{d t}=K_{\mathrm{mTOR}}-K_{\mathrm{mTOR}} \cdot K_{\mathrm{M} 2} \cdot \operatorname{pre}_{\mathrm{pmTOR}} ; \operatorname{pre}_{\mathrm{pmTOR}}(0)=1 \\
\frac{d \mathrm{pmTOR}}{d t}=K_{\mathrm{mTOR}} \cdot K_{\mathrm{M} 2} \cdot \operatorname{pre}_{\mathrm{pmTOR}}-K_{\mathrm{mTOR}} \cdot \operatorname{pmTOR} ; \operatorname{pmTOR}(0)=1
\end{gathered}
$$

where $K_{\mathrm{M} 1}$ and $K_{\mathrm{M} 2}$ represent transit compartments, $\tau_{\mathrm{MP}}$ represents the mean transit time for the delay of paclitaxel-mediated signaling between pAkt and pmTOR, $\mathrm{K}_{\mathrm{mTOR}}$ represents the turnover rate constant for pmTOR, and $S_{1 \mathrm{P}}$ represents the coefficient for inhibition of mTOR activity due to paclitaxel.

In addition, caspase-3 (Cas3 in the equations), the executioner of apoptosis, is activated in response to paclitaxel treatment. Its activity over time was captured well with three transit compartments as shown in eqs. 8-10, which led to the production of active caspase-3 described by a precursor pool indirect response model (Fig. 1). A negative retroregulation loop from the active caspase-3 compartment (Cas3) to the first transit compartment $\left(K_{\mathrm{C} 1}\right)$ allowed to capture the tolerance phenomenon observed in the caspase-3 activity temporal profile (i.e., return to the baseline activity level for Cas3 while JIMT-1 cells are still exposed to paclitaxel).

$$
\begin{gathered}
\frac{d K_{\mathrm{C} 1}}{d t}=\left(\frac{1}{\tau_{\mathrm{CP}}}\right) \cdot\left(\left(\frac{1+\left(\left(k_{\mathrm{P}} \cdot C_{\mathrm{P}}\right)^{S 2_{\mathrm{P}}}\right)}{\mathrm{Cas}^{S 3_{\mathrm{P}}}}\right)-K_{\mathrm{C} 1}\right) ; K_{\mathrm{C} 1}(0)=1 \\
\frac{d K_{\mathrm{C} 2}}{d t}=\left(\frac{1}{\tau_{\mathrm{CP}}}\right) \cdot\left(K_{\mathrm{C} 1}-K_{\mathrm{C} 2}\right) ; K_{\mathrm{C} 2}(0)=1 \\
\frac{d K_{\mathrm{C} 3}}{d t}=\left(\frac{1}{\tau_{\mathrm{CP}}}\right) \cdot\left(K_{\mathrm{C} 2}-K_{\mathrm{C} 3}\right) ; K_{\mathrm{C} 3}(0)=1 \\
\frac{d \mathrm{pre}_{\mathrm{Cas} 3}}{d t}=K_{\mathrm{cas}}-K_{\mathrm{cas}} \cdot \operatorname{pre}_{\mathrm{Cas} 3} \cdot K_{\mathrm{C} 3} ; \operatorname{pre}_{\mathrm{Cas} 3}(0)=1 \\
\frac{d \mathrm{Cas} 3}{d t}=K_{\mathrm{cas}} \cdot \operatorname{pre}_{\mathrm{Cas} 3} \cdot K_{\mathrm{C} 3}-K_{\mathrm{cas}} \cdot \operatorname{Cas} 3 ; \operatorname{Cas} 3(0)=1
\end{gathered}
$$

where $k_{\mathrm{P}}$ and $S 2_{\mathrm{P}}$ represent the slope and exponent for stimulatory effect of paclitaxel on caspase- 3 activity, $\tau_{\mathrm{CP}}$ represents the mean 
transit time for paclitaxel-mediated caspase-3 activation signaling, $K_{\text {cas }}$ represents the turnover rate constant for caspase-3 activity, and $S 3_{\mathrm{P}}$ represents the feedback coefficient for caspase-3 activity.

The changes in protein activity were linked to JIMT-1 cellular response as follows:

$$
\frac{d R}{d t}=\left(\operatorname{pmTOR}^{S 4_{\mathrm{P}}}\right) \cdot k g \cdot R-k d_{\mathrm{P}} \cdot R \cdot(\mathrm{Cas} 3-1) ; R(0)=R_{0}
$$

where $R$ represents cell viability response, and $R_{0}$ represents initial number of cells at time 0 . Because all data were normalized to the control arm, $R_{0}$ was equal to 1 .

In the 2D experimental studies, JIMT-1 cells exhibited an exponential pattern in their growth over time under control conditions (no treatment). Therefore, $\mathrm{kg}$, the first-order growth rate constant, was used to quantify the JIMT-1 cellular proliferation rate. The protein signal from the pmTOR compartment (eq. 7) influenced the inhibition of JIMT-1 cell growth, and its effect was incorporated using the exponent $S 4_{\mathrm{P}}$. The $k d_{\mathrm{P}}$ parameter represents the death rate constant for JIMT-1 cells and was used to stimulate JIMT-1 cells death driven by caspase-3 activity. The subscript "P" in the above set of equations stands for all paclitaxel-associated parameters.

Dasatinib. Protein modeling for dasatinib included the inhibition of its target protein pSrc via dephosphorylation, followed by the inhibition of its downstream proteins pAkt and pmTOR, as described by the following equations:

$$
\begin{aligned}
& \frac{d \text { pre }_{\mathrm{pSrc}}}{d t}=K_{\mathrm{src}}-K_{\mathrm{src}} \cdot \operatorname{pre}_{\mathrm{pSrc}} \cdot\left(1-\left(C_{\mathrm{D}} \cdot S 1_{\mathrm{D}}\right)\right) ; \operatorname{pre}_{\mathrm{pSrc}}(0)=1 \\
& \frac{d \mathrm{pSrc}}{d t}=K_{\mathrm{src}} \cdot \operatorname{pre}_{\mathrm{pSrc}} \cdot\left(1-\left(C_{\mathrm{D}} \cdot S 1_{\mathrm{D}}\right)\right)-K_{\mathrm{src}} \cdot \mathrm{pSrc} ; \operatorname{pSrc}(0)=1 \\
& \frac{d \text { pre }_{\mathrm{pAkt}}}{d t}=K_{\mathrm{Akt}}-K_{\mathrm{Akt}} \cdot \text { pre }_{\mathrm{pAkt}} ; \operatorname{pre}_{\mathrm{pAkt}}(0)=1 \\
& \frac{d \mathrm{pAkt}}{d t}=K_{\mathrm{Akt}} \cdot \operatorname{pre}_{\mathrm{pAkt}}-K_{\mathrm{Akt}} \cdot \frac{\mathrm{pAkt}}{\mathrm{pSrc}^{S 2_{\mathrm{D}}}} ; \operatorname{pAkt}(0)=1 \\
& \frac{d K_{\mathrm{M} 1}}{d t}=\left(\frac{1}{\tau_{\mathrm{MD}}}\right) \cdot\left(\left(\mathrm{pAkt}^{S 3_{\mathrm{D}}}\right)-K_{\mathrm{M} 1}\right) ; K_{\mathrm{M} 1}(0)=1 \\
& \frac{d K_{\mathrm{M} 2}}{d t}=\left(\frac{1}{\tau_{\mathrm{MD}}}\right) \cdot\left(K_{\mathrm{M} 1}-K_{\mathrm{M} 2}\right) ; K_{\mathrm{M} 2}(0)=1 \\
& \frac{d \text { pre }_{\mathrm{pmTOR}}}{d t}=K_{\mathrm{mTOR}}-K_{\mathrm{mTOR}} \cdot K_{\mathrm{M} 2} \cdot \text { pre }_{\mathrm{pmTOR}} ; \operatorname{pre}_{\mathrm{pmTOR}}(0)=1 \\
& \frac{d \mathrm{pmTOR}}{d t}=K_{\mathrm{mTOR}} \cdot K_{\mathrm{M} 2} \cdot \operatorname{pre} \mathrm{pmTOR}-K_{\mathrm{mtor}} \cdot \operatorname{pmTOR} ; \operatorname{pmTOR}(0)=1 \\
& \frac{d R}{d t}=\left(\mathrm{pmTOR}^{S 4_{\mathrm{D}}}\right) \cdot k g \cdot R ; R(0)=R_{0}
\end{aligned}
$$

A precursor pool-based indirect response model was used to capture pSrc inhibition under dasatinib treatment and to characterize the return to baseline phase after 9 hours of pSrc inhibition (Fig. 2). $K_{\text {Src }}$ represents the turnover rate constant for $\mathrm{pSrc}, C_{\mathrm{D}}$ is the dasatinib concentration $(50 \mathrm{nM})$, and $\mathrm{S} 1_{\mathrm{D}}$ is the coefficient for inhibition of $\mathrm{pSrc}$ due to the dasatinib effect. $\mathrm{S} 2 \mathrm{D}$ represents the coefficient for effect of pSrc on pAkt, wherein Akt activity is inhibited via stimulation of loss of pAkt due to inhibition of Src (Liao and Hung, 2010). The mTOR activity is then inhibited due to pAkt via two transit compartments, $K_{\mathrm{M} 1}$ and $K_{\mathrm{M} 2}$, with $\tau_{\mathrm{MD}}$ as the mean transit time and $\mathrm{S} 3_{\mathrm{D}}$ as the coefficient of inhibition. The inhibition of mTOR activity drives the inhibition of JIMT-1 cellular response as shown in eq. 22. The subscript "D" stands for all dasatinib-associated parameters, and all other terms have the usual notations described previously.

Everolimus. The final QSP model for everolimus integrated inhibition of the pmTOR protein, followed by a stimulatory feedback loop from pmTOR on the pAkt protein, in accordance with the reported literature and our observed pAkt activity data (Fig. 2). Notably, an increase in Src activity in response to everolimus treatment was also observed. This is in line with the finding that rapamycin, an mTORC1 inhibitor, causes phosphorylation and transactivation of the epidermal growth factor receptor (EGFR) pathway via Src activation in some cell lines, thus promoting cell survival (Chaturvedi et al., 2009). In addition, induction of IRS-1 and the release of feedback inhibition of the IGF-1R/PI3K pathway cause $A k t$ overactivation, which promotes cell growth in the presence of everolimus alone (O'Reilly et al., 2006). The model equations governing protein dynamics are as follows:

$$
\begin{aligned}
\frac{d \text { pre }_{\mathrm{pmTOR}}}{d t} & =K_{\mathrm{mTOR}}-K_{\mathrm{mTOR}} \cdot \operatorname{pre}_{\mathrm{pmTOR}} \cdot\left(1-C_{\mathrm{E}} \cdot S 1_{\mathrm{E}}\right) \cdot\left(\mathrm{pAkt}^{S 2_{\mathrm{E}}}\right) ; \\
\text { pre }_{\mathrm{pmTOR}}(0) & =1
\end{aligned}
$$

$\frac{d \mathrm{pmTOR}}{d t}=K_{\mathrm{mTOR}} \cdot \mathrm{pre}_{\mathrm{pmTOR}} \cdot\left(1-C_{E} \cdot S 1_{\mathrm{E}}\right) \cdot\left(\mathrm{pAkt}^{S 2_{\mathrm{E}}}\right)-K_{\mathrm{mTOR}} \cdot \mathrm{pmTOR} ;$ $\operatorname{pmTOR}(0)=1$

$$
\begin{aligned}
& \frac{d K_{S 1}}{d t}=\left(\frac{1}{\tau_{\mathrm{SE}}}\right) \cdot\left(\left(\operatorname{pmTOR}^{S 3_{\mathrm{E}}}\right)-K_{S 1}\right) \\
& \frac{d K_{S 2}}{d t}=\left(\frac{1}{\tau_{\mathrm{SE}}}\right) \cdot\left(K_{S 1}-K_{S 2}\right) ; K_{S 2}(0)=1 \\
& \frac{d K_{S 3}}{d t}=\left(\frac{1}{\tau_{S E}}\right) \cdot\left(K_{S 2}-K_{S 3}\right) ; K_{S 3}(0)=1 \\
& \frac{d \text { pre }_{\mathrm{pSrc}}}{d t}=K_{\mathrm{src}}-K_{\mathrm{src}} \cdot \frac{\text { pre }_{\mathrm{pSrc}}}{K_{S 3}} ; \operatorname{pre}_{\mathrm{pSrc}}(0)=1 \\
& \frac{d \mathrm{pSrc}}{d t}=K_{\mathrm{src}} \cdot \frac{\mathrm{pre}_{\mathrm{pSrc}}}{K_{S 3}}-K_{\mathrm{src}} \cdot \mathrm{pSrc} ; \operatorname{pSrc}(0)=1 \\
& \frac{d \text { pre }_{\mathrm{pAkt}}}{d t}=K_{\mathrm{Akt}}-K_{\mathrm{Akt}} \cdot \frac{\text { pre }_{\mathrm{pAkt}}}{\text { pmTOR }^{S 4_{\mathrm{E}}}} ; \operatorname{pre}_{\mathrm{pAkt}}(0)=1 \\
& \frac{d \mathrm{pAkt}}{d t}=K_{\mathrm{Akt}} \cdot \frac{\mathrm{pre}_{\mathrm{pAkt}}}{\mathrm{pmTOR}^{S 4_{\mathrm{E}}}}-K_{\mathrm{Akt}} \cdot \frac{\mathrm{pAkt}}{\mathrm{pSrc}^{S 5_{\mathrm{E}}}} ; \operatorname{pAkt}(0)=1 \\
& \frac{d R}{d t}=\left(\operatorname{pmTOR}^{S 6_{\mathrm{E}}}\right) \cdot k g \cdot R ; R(0)=R_{0}
\end{aligned}
$$

where $C_{\mathrm{E}}$ is the everolimus concentration $(50 \mathrm{nM})$ and $S 1_{\mathrm{E}}$ is everolimus coefficient of inhibition on pmTOR. Feedback activation of pSrc due to pmTOR was driven by three transit compartments. The pmTOR activity drove the inhibition of the proliferation of JIMT-1 cells as represented in eq. 32. The subscript "E" denotes everolimus-associated model terms and parameters.

Of note, there was no increase in caspase-3 activity observed in response to the everolimus or dasatinib treatments, indicating a cytostatic effect of these two agents in JIMT-1 cells.

Dual Combination Therapy of Dasatinib with Everolimus (DE). The dual therapy model included components of the individual models for each agent in the combination with attenuation of the feedback activation loops due to counterregulatory mechanisms of dasatinib on everolimus. In addition, an active caspase-3 component was included in the model due to slight elevation in active caspase-3 expression observed with the dual combination (Fig. 3). The corresponding model equations are as follows:

$$
\begin{aligned}
\frac{d \text { pre }_{\mathrm{pmTOR}}}{d t} & =K_{\mathrm{mTOR}}-K_{\mathrm{mTOR}} \cdot \operatorname{pre}_{\mathrm{pmTOR}} \cdot\left(1-C_{\mathrm{E}} \cdot S 1_{\mathrm{E}}\right) \cdot\left(\mathrm{pAkt}^{S 1_{\mathrm{DE}}}\right) ; \\
\text { pre }_{\mathrm{pmTOR}}(0) & =1
\end{aligned}
$$
$\frac{d \mathrm{pmTOR}}{d t}=K_{\mathrm{mTOR}} \cdot \operatorname{pre}_{\mathrm{pmTOR}} \cdot\left(1-C_{\mathrm{E}} \cdot S 1_{E}\right) \cdot\left(\mathrm{pAkt}^{S 1_{\mathrm{DE}}}\right)-K_{\mathrm{mTOR}} \cdot \mathrm{pmTOR} ;$
$\operatorname{pmTOR}(0)=1$

$$
\frac{d \mathrm{pre}_{\mathrm{pSrc}}}{d t}=K_{\mathrm{src}}-K_{\mathrm{src}} \cdot \operatorname{pre}_{\mathrm{pSrc}} \cdot\left(1-\left(C_{\mathrm{D}} \cdot S 1_{\mathrm{D}}\right)\right) ; \operatorname{pre}_{\mathrm{pSrc}}(0)=1
$$




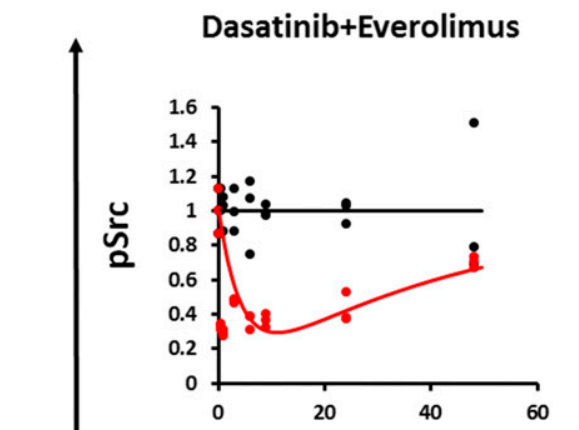

Paclitaxel+Dasatinib+Everolimus
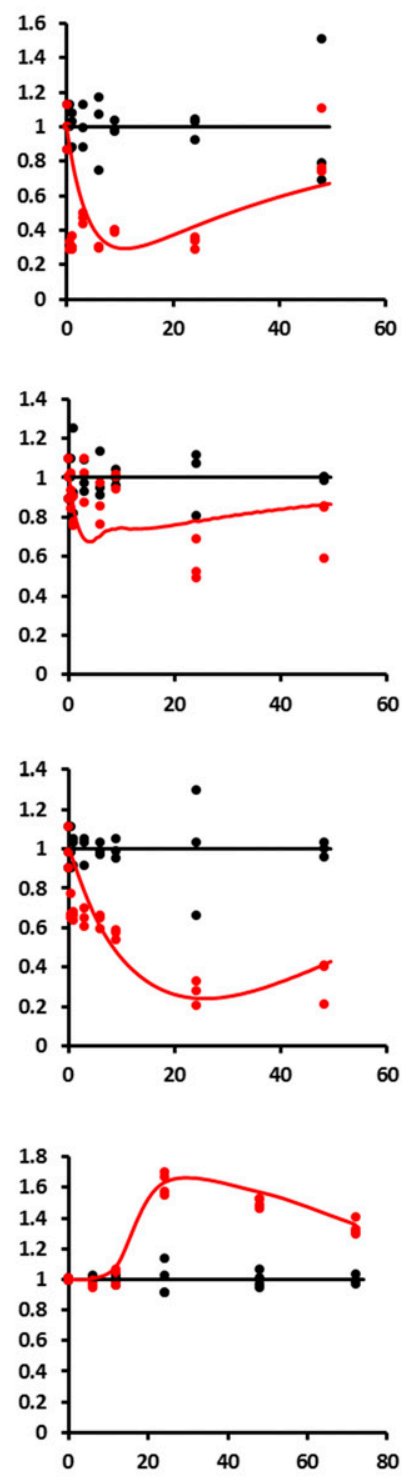

\section{Paclitaxel $\rightarrow$ (Dasatinib+Everolimus)}
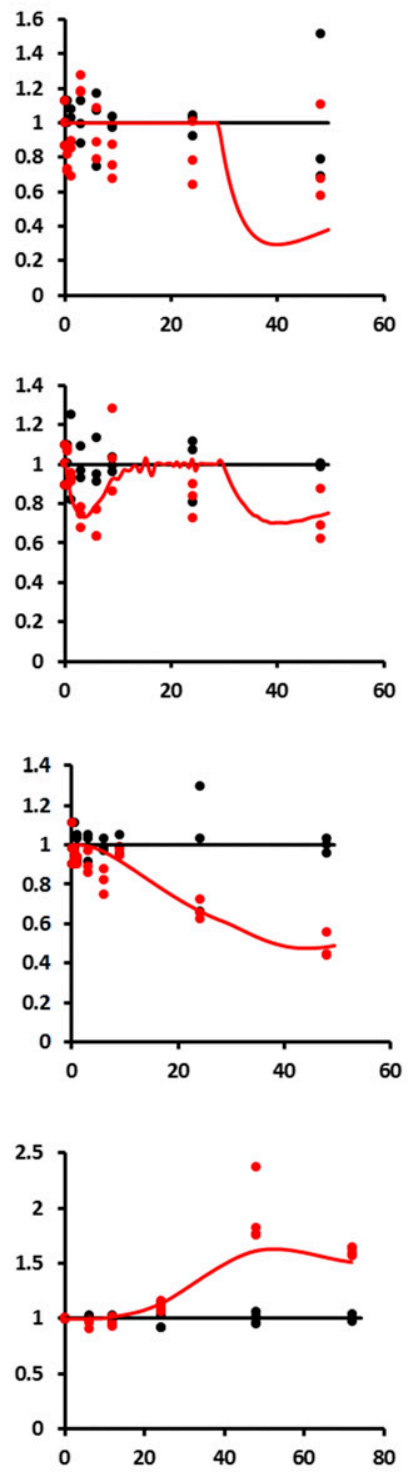

Time (h)

Fig. 3. Time course of cellular protein dynamics after continuous exposure of JIMT-1 cells to combination therapies: DE simultaneous treatment with dasatinib + everolimus at $50 \mathrm{nM}$ each, PDE simultaneous treatment with paclitaxel + dasatinib + everolimus at $50 \mathrm{nM}$ each, and P(DE) sequential treatment with paclitaxel (24 hours prior) + (dasatinib + everolimus) at $50 \mathrm{nM}$ each. Relative protein expression profiles are shown for pSrc, pAkt, pmTOR, and Caspase-3 activities for all combinations. Black circles represent observed data under control conditions, and red circles represent observed data under treatment conditions. Solid lines represent model fittings.

$$
\begin{gathered}
\frac{d \mathrm{pSrc}}{d t}=K_{\mathrm{src}} \cdot \operatorname{pre}_{\mathrm{pSrc}} \cdot\left(1-\left(C_{\mathrm{D}} \cdot S 1_{\mathrm{D}}\right)\right)-K_{\mathrm{src}} \cdot \mathrm{pSrc} ; \mathrm{pSrc}(0)=1 \\
\frac{d \mathrm{pre}_{\mathrm{pAkt}}}{d t}=K_{\mathrm{Akt}}-K_{\mathrm{Akt}} \cdot \frac{\mathrm{pre}_{\mathrm{pAkt}}}{\mathrm{pmTOR}^{S 4_{\mathrm{E}}}} ; \operatorname{pre}_{\mathrm{pAkt}}(0)=1 \\
\frac{d \mathrm{pAkt}}{d t}=K_{\mathrm{Akt}} \cdot \frac{\mathrm{pre}_{\mathrm{pAkt}}}{\mathrm{pmTOR}^{S 4_{\mathrm{E}}}}-K_{\mathrm{Akt}} \cdot \frac{\mathrm{pAkt}}{\mathrm{pSrc}^{S 2_{\mathrm{D}}}} ; \operatorname{pAkt}(0)=1 \\
\frac{d K_{\mathrm{C} 1}}{d t}=\left(\frac{1}{\tau_{\mathrm{CDE}}}\right) \cdot\left(\left(\frac{1+\left(\left(k_{\mathrm{DE}} \cdot C_{\mathrm{DE}}\right)^{S 2_{\mathrm{DE}}}\right)}{\mathrm{CaS} 3}\right)-K_{\mathrm{C} 1}\right) ; K_{\mathrm{C} 1}(0)=1 \\
\frac{d K_{\mathrm{C} 2}}{d t}=\left(\frac{1}{\tau_{\mathrm{CDE}}}\right) \cdot\left(K_{\mathrm{C} 1}^{S 3_{\mathrm{DE}}}-K_{\mathrm{C} 2}\right) ; K_{\mathrm{C} 2}(0)=1
\end{gathered}
$$

$$
\begin{array}{r}
\frac{d \mathrm{pre}_{\mathrm{Cas} 3}}{d t}=K_{\mathrm{cas}}-K_{\mathrm{cas}} \cdot \operatorname{pre}_{\mathrm{Cas} 3} \cdot K_{\mathrm{C} 2} ; \operatorname{pre}_{\mathrm{Cas} 3}(0)=1 \\
\frac{d \mathrm{Cas} 3}{d t}=K_{\mathrm{cas} \cdot} \cdot \operatorname{pre}_{\mathrm{Cas} 3} \cdot K_{\mathrm{C} 2}-K_{\mathrm{cas}} \cdot \operatorname{Cas} 3 ; \operatorname{Cas} 3(0)=1 \\
\frac{d R}{d t}=\left(\mathrm{pmTOR}^{S 4_{\mathrm{DE}}}\right) \cdot k g \cdot R-k d_{\mathrm{DE}} \cdot R \cdot(\operatorname{cas} 3-1) ; R(0)=R_{0}
\end{array}
$$

where $\mathrm{C}_{\mathrm{DE}}$ denotes concentration of dasatinib and everolimus ( $\left.50 \mathrm{nM}\right)$, and the subscript "DE" denotes dasatinib-everolimus-associated terms and parameters. $S 1_{\mathrm{DE}}$ is the coefficient for effect of pAkt on pmTOR in the presence of DE treatment, $k_{\mathrm{DE}}$ and $S 2_{\mathrm{DE}}$ are the slope and exponent for activation of caspase-3, and $\tau_{\mathrm{CDE}}$ is 
the mean transit time for delay in active caspase-3 production. $S 3_{\mathrm{DE}}$ represents an exponent used for modulation of signaling intensity by amplification to compensate for attenuation of signal due to time delays required to characterize observed caspase-3 activity (Sun and Jusko, 1998; Mager and Jusko, 2001). $S 4_{\mathrm{DE}}$ represents the coefficient of cell growth inhibition due to pmTOR with $\mathrm{DE}$ treatment, and $k d_{\mathrm{DE}}$ is the cell death rate constant for JIMT-1 cells with DE treatment.

Triple Combination Therapy of Paclitaxel with DE. QSP models were built to characterize the effect of PDE and P(DE) treatments on selected proteins and JIMT-1 cells. PDE refers to concomitant administration of paclitaxel with $\mathrm{DE}$, whereas, $\mathrm{P}(\mathrm{DE})$ refers to paclitaxel administered 24 hours before DE. The final combination QSP models integrated components from the individual agent QSP models with attenuation of feedback activation loops on Src and Akt. The mathematical equations for PDE treatment are as follows:

$$
\begin{aligned}
& \frac{d \text { pre }_{\mathrm{pmTOR}}}{d t}=K_{\mathrm{mTOR}}-K_{\mathrm{mTOR}} \cdot \operatorname{pre}_{\mathrm{pmTOR}} \cdot\left(1-C_{\mathrm{E}} \cdot S 1_{\mathrm{E}}\right) \cdot\left(\mathrm{pAkt}^{S 1_{\mathrm{PDE}}}\right) \\
& \operatorname{pre}_{\mathrm{pmTOR}}(0)=1
\end{aligned}
$$

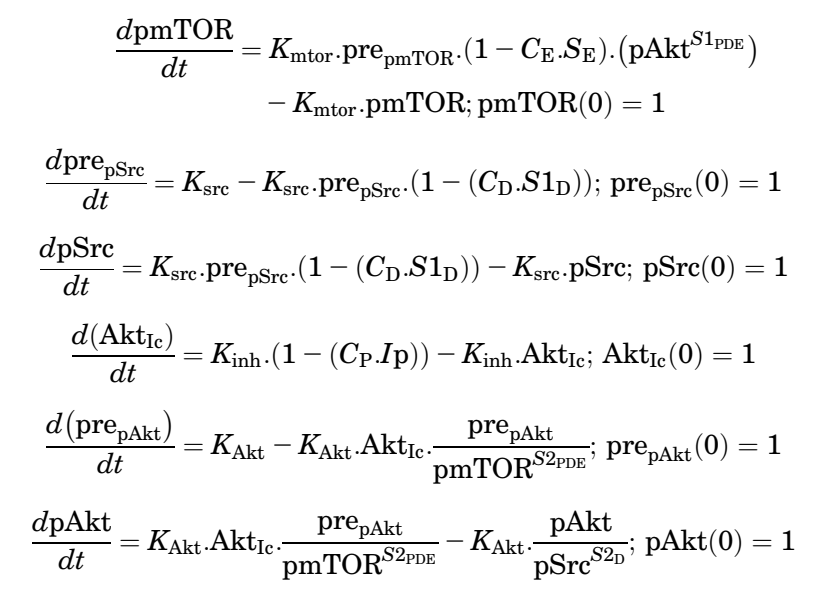

$\frac{d K_{\mathrm{C} 1}}{d t}=\left(\frac{1}{\tau_{\mathrm{CPDE}}}\right) \cdot\left(\left(\frac{1+\left(\left(k_{\mathrm{DE}} \cdot C_{\mathrm{DE}}\right)^{S 2_{\mathrm{DE}}}\right)+\left(\left(k_{\mathrm{P}} \cdot C_{\mathrm{P}}\right)^{S 2_{\mathrm{P}}}\right)}{\mathrm{Cas} 3}\right)-K_{\mathrm{C} 1}\right)$ $K_{\mathrm{C} 1}(0)=1$

$$
\begin{gathered}
\frac{d K_{\mathrm{C} 2}}{d t}=\left(\frac{1}{\tau_{\mathrm{CPDE}}}\right) \cdot\left(K_{\mathrm{C} 1}-K_{\mathrm{C} 2}\right) ; K_{\mathrm{C} 2}(0)=1 \\
\frac{d K_{\mathrm{C} 3}}{d t}=\left(\frac{1}{\tau_{\mathrm{CPDE}}}\right) \cdot\left(K_{\mathrm{C} 2}-K_{\mathrm{C} 3}\right) ; K_{\mathrm{C} 2}(0)=1 \\
\frac{d \text { pre }_{\mathrm{Cas} 3}}{d t}=K_{\mathrm{cas}}-K_{\mathrm{cas} \cdot} \cdot \operatorname{pre}_{\mathrm{Cas} 3} \cdot K_{\mathrm{C} 3} ; \operatorname{pre}_{\mathrm{Cas} 3}(0)=1 \\
\frac{d \mathrm{Cas} 3_{\mathrm{cas}} \cdot \operatorname{pre}_{\mathrm{Cas} 3} \cdot K_{\mathrm{C} 3}-K_{\mathrm{cas}} \cdot \operatorname{Cas} 3 ; \operatorname{Cas} 3(0)=1}{d t}=K_{\mathrm{dR}}=\left(\mathrm{pmTOR}^{S 3_{\mathrm{PDE}}}\right) \cdot k g \cdot R-k d_{\mathrm{PDE}} \cdot R \cdot(\operatorname{cas} 3-1) ; R(0)=R_{0}
\end{gathered}
$$

where $S 1_{\mathrm{PDE}}$ represents the effect of pAkt on pmTOR and $S 2_{\mathrm{PDE}}$ represents the coefficient for feedback activation of pAkt due to pmTOR in the presence of PDE treatment. $S 3_{\mathrm{PDE}}$ represents the coefficient of inhibition of cell growth due to mTOR activity, and $\tau_{\mathrm{PDE}}$ represents the mean transit time for activation of caspase-3. The subscript "PDE" denotes paclitaxel + dasatinib + everolimus-associated terms and parameters.

The mathematical equations for the sequential combination $\mathrm{P}(\mathrm{DE})$ are as follows for time $<24$ hours:

$$
\frac{d\left(\mathrm{Akt}_{\mathrm{Ic}}\right)}{d t}=K_{\mathrm{inh}} \cdot\left(1-\left(C_{\mathrm{P}} \cdot \mathrm{Ip}\right)\right)-K_{\mathrm{inh}} \cdot \mathrm{Akt}_{\mathrm{Ic}} ; \mathrm{Akt}_{\mathrm{Ic}}(0)=1
$$

$$
\begin{gathered}
\frac{d\left(\text { pre }_{\mathrm{pAkt}}\right)}{d t}=K_{\mathrm{Akt}}-K_{\mathrm{Akt}} \cdot \mathrm{Akt}_{\mathrm{Ic}} \cdot \operatorname{pre}_{\mathrm{pAkt}} ; \operatorname{pre}_{\mathrm{pAkt}}(0)=1 \\
\frac{d \mathrm{pAkt}}{d t}=K_{\mathrm{Akt}} \cdot \mathrm{Akt}_{\mathrm{Ic}} \cdot \operatorname{pre}_{\mathrm{pAkt}}-K_{\mathrm{Akt}} \cdot \mathrm{pAkt} ; \operatorname{pAkt}(0)=1 \\
\frac{d K_{\mathrm{M} 1}}{d t}=\left(\frac{1}{\tau_{\mathrm{MP}}}\right) \cdot\left(\left(\mathrm{pAkt}^{S 1_{\mathrm{P}}}\right)-K_{\mathrm{M} 1}\right) ; K_{\mathrm{M} 1}(0)=1 \\
\frac{d K_{\mathrm{M} 2}}{d t}=\left(\frac{1}{\tau_{\mathrm{MP}}}\right) \cdot\left(K_{\mathrm{M} 1}-K_{\mathrm{M} 2}\right) ; K_{\mathrm{M} 2}(0)=1
\end{gathered}
$$

$\frac{d\left(\text { pre }_{\mathrm{pmTOR}}\right)}{d t}=K_{\mathrm{mTOR}}-K_{\mathrm{mTOR}} \cdot K_{\mathrm{M} 2} \cdot \operatorname{pre}_{\mathrm{pmTOR}} ; \operatorname{pre}_{\mathrm{pmTOR}}(0)=1$

$\frac{d \mathrm{pmTOR}}{d t}=K_{\mathrm{mTOR}} \cdot K_{\mathrm{M} 2} \cdot \mathrm{pre}_{\mathrm{pmTOR}}-K_{\mathrm{mTOR}} \cdot \operatorname{pmTOR} ; \operatorname{pmTOR}(0)=1$

$$
\begin{aligned}
& \frac{d \text { pre }_{\mathrm{pSrc}}}{d t}=K_{\mathrm{src}}-K_{\mathrm{src}} \cdot \text { pre }_{\mathrm{pSrc}} ; \text { pre }_{\mathrm{pSrc}}(0)=1 \\
& \frac{d \mathrm{pSrc}}{d t}=K_{\mathrm{src}} \cdot \operatorname{pre}_{\mathrm{pSrc}}-K_{\mathrm{src}} \cdot \operatorname{pSrc} ; \operatorname{pSrc}(0)=1 \\
& \frac{d K_{\mathrm{C} 1}}{d t}=\left(\frac{1}{\tau_{\mathrm{CP}}}\right) \cdot\left(\left(\frac{1+\left(\left(k_{\mathrm{P}} \cdot C_{\mathrm{P}}\right)^{S 2_{\mathrm{P}}}\right)}{\mathrm{Cas} 3^{S 3 \mathrm{P}}}\right)-K_{\mathrm{C} 1}\right) ; K_{\mathrm{C} 1}(0)=1 \\
& \frac{d K_{\mathrm{C} 2}}{d t}=\left(\frac{1}{\tau_{\mathrm{CP}}}\right) \cdot\left(K_{\mathrm{C} 1}-K_{\mathrm{C} 2}\right) ; K_{\mathrm{C} 2}(0)=1 \\
& \frac{d K_{\mathrm{C} 3}}{d t}=\left(\frac{1}{\tau_{\mathrm{CP}}}\right) \cdot\left(K_{\mathrm{C} 2}-K_{\mathrm{C} 3}\right) ; K_{\mathrm{C} 3}(0)=1 \\
& \frac{d \text { pre }_{\text {Cas } 3}}{d t}=K_{\text {cas }}-K_{\text {cas }} \cdot \operatorname{pre}_{\mathrm{Cas} 3} \cdot K_{\mathrm{C} 3} ; \operatorname{pre}_{\mathrm{Cas} 3}(0)=1 \\
& \frac{d \mathrm{Cas} 3}{d t}=K_{\mathrm{cas}} \cdot \mathrm{pre}_{\mathrm{Cas} 3} \cdot K_{\mathrm{C} 3}-K_{\mathrm{cas}} \cdot \operatorname{Cas} 3 ; \operatorname{Cas} 3(0)=1 \\
& \frac{d R}{d t}=\left(\operatorname{pmTOR}^{S 4_{\mathrm{P}}}\right) \cdot k g \cdot R-k d_{\mathrm{P}} \cdot R \cdot(\operatorname{cas} 3-1) ; R(0)=R_{0}
\end{aligned}
$$

For time $\geq 24$ hours:

$$
\begin{gathered}
\frac{d\left(\mathrm{Akt}_{\mathrm{Ic}}\right)}{d t}=K_{\mathrm{inh}} \cdot\left(1-\left(C_{\mathrm{P}} \cdot I \mathrm{p}\right)\right)-K_{\mathrm{inh}} \cdot \mathrm{Akt}_{\mathrm{Ic}} ; \mathrm{Akt}_{\mathrm{Ic}}(0)=1 \frac{1}{2} \\
\frac{d\left(\mathrm{pre}_{\mathrm{pAkt}}\right)}{d t}=K_{\mathrm{Akt}}-K_{\mathrm{Akt}} \cdot \mathrm{Akt}_{\mathrm{Ic}} \cdot \frac{\operatorname{pre}_{\mathrm{pAkt}}}{\operatorname{pmTOR}^{S 2_{\mathrm{P}(\mathrm{DE})}} ; \operatorname{pre}_{\mathrm{pAkt}}(0)=1} \\
\frac{d \mathrm{pAkt}}{d t}=K_{\mathrm{Akt}} \cdot \mathrm{Akt}_{\mathrm{Ic}} \cdot \frac{\operatorname{pre}_{\mathrm{pAkt}}}{\mathrm{pmTOR}^{S 2_{\mathrm{P}(\mathrm{DE})}}}-K_{\mathrm{Akt}} \cdot \frac{\mathrm{pAkt}}{\mathrm{pSrc}^{S 2_{\mathrm{D}}}} ; \operatorname{pAkt}(0)=1
\end{gathered}
$$

$\frac{d \text { pre }_{\mathrm{pmTOR}}}{d t}=K_{\mathrm{mTOR}}-K_{\mathrm{mTOR}} \cdot \operatorname{pre}_{\mathrm{pmTOR}} \cdot\left(1-C_{\mathrm{E}} \cdot S 1_{\mathrm{E}}\right) \cdot\left(\mathrm{pAkt}^{\left.S 1_{\mathrm{P}(\mathrm{DE})}\right)}\right)$ $\operatorname{pre}_{\text {pmTOR }}(0)=1$

$$
\begin{aligned}
& \frac{d \mathrm{pre}_{\mathrm{pSrc}}}{d t}=K_{\mathrm{src}}-K_{\mathrm{src}} \cdot \operatorname{pre}_{\mathrm{pSrc}} \cdot\left(1-\left(C_{\mathrm{D}} \cdot S 1_{\mathrm{D}}\right)\right) ; \operatorname{pre}_{\mathrm{pSrc}}(0)=1 \\
& \frac{d \mathrm{pSrc}}{d t}=K_{\mathrm{src}} \cdot \operatorname{pre}_{\mathrm{pSrc}} \cdot\left(1-\left(C_{\mathrm{D}} \cdot S 1_{\mathrm{D}}\right)\right)-K_{\mathrm{src}} \cdot \operatorname{pSrc} ; \operatorname{pSrc}(0)=1
\end{aligned}
$$

$\frac{d K_{\mathrm{C} 1}}{d t}=\left(\frac{1}{\tau_{\mathrm{CPDE}}}\right) \cdot\left(\left(\frac{1+\left(\left(k_{\mathrm{DE}} \cdot C_{\mathrm{DE}}\right)^{S 2_{\mathrm{DE}}}\right)+\left(\left(k_{\mathrm{P}} \cdot C_{\mathrm{P}}\right)^{S 2_{\mathrm{P}}}\right)}{\mathrm{Cas} 3}\right)-K_{\mathrm{C} 1}\right)$

$K_{\mathrm{C} 1}(0)=1$ 


$$
\begin{gathered}
\frac{d K_{\mathrm{C} 2}}{d t}=\left(\frac{1}{\tau_{\mathrm{CPDE}}}\right) \cdot\left(K_{\mathrm{C} 1}-K_{\mathrm{C} 2}\right) ; K_{\mathrm{C} 2}(0)=1 \\
\frac{d K_{\mathrm{C} 3}}{d t}=\left(\frac{1}{\tau_{\mathrm{CPDE}}}\right) \cdot\left(K_{\mathrm{C} 2}-K_{\mathrm{C} 3}\right) ; K_{\mathrm{C} 3}(0)=1 \\
\frac{d \text { pre }_{\mathrm{Cas} 3}}{d t}=K_{\mathrm{cas}}-K_{\mathrm{cas} \cdot} \cdot \operatorname{pre}_{\mathrm{Cas} 3} \cdot K_{\mathrm{C} 3} ; \operatorname{pre}_{\mathrm{Cas} 3}(0)=1 \\
\frac{d \mathrm{Cas} 3}{d t}=K_{\mathrm{cas}} \cdot \operatorname{pre}_{\mathrm{Cas} 3} \cdot K_{\mathrm{C} 3}-K_{\mathrm{cas}} \cdot \operatorname{Cas} 3 ; \operatorname{Cas} 3(0)=1 \\
\frac{d R}{d t}=\left(\mathrm{pmTOR}^{S 3_{\mathrm{PDE}}}\right) \cdot \mathrm{kg} \cdot R-k d_{\mathrm{PDE}} \cdot R \cdot(\operatorname{cas} 3-1) ; R(0)=R_{0}
\end{gathered}
$$

Before administration of DE ( $<24$ hours), the model equations for single-agent paclitaxel were employed; after 24 hours, the model equations for the PDE simultaneous model were used. The only difference between the $\mathrm{P}(\mathrm{DE})$ and PDE model parameters is the coefficient for feedback activation of pAkt due to pmTOR $\left(S 2_{\mathrm{P}(\mathrm{DE})}\right.$ and $\left.S 2_{\mathrm{PDE}}\right)$ and the coefficient for effect of pAkt on pmTOR $\left(S 1_{\mathrm{P}(\mathrm{DE})}\right.$ and $S 1_{\mathrm{PDE}}$ ) as a result of different degrees of feedback signal attenuation with the two treatment regimens.

There are three key features of all the mathematical models in the 2D experimental setting. 1) All measured protein activities are characterized using precursor-pool based indirect response models, with common turnover rate constants across all treatment arms (system parameters). 2) Data from all treatment arms were normalized to the no-treatment control arm. Thus, homeostasis is maintained for the protein dynamic data in the control arm at a value of one unit so as to satisfy the law of mass balance, and all protein initial conditions are set to unity. 3) Protein activity perturbations due to the various treatment arms are introduced with the help of stimulatory or inhibitory coefficients and transit compartments, as applicable (drug-related parameters).

\section{QSP and PK/PD Models for Protein and Cellular Responses in the 3DD Cell Culture Setting}

A PK/PD study was conducted in the 3DD cell culture system to assess the efficacy of the triple and sequential combination therapy in JIMT-1 cells, as described in our previously published work (Ande et al., 2018). Briefly, paclitaxel was administered as a 3-hour shortterm intravenous infusion on day 0 . After 24 hours, the combination DE was administered as a constant exposure for 72 hours (days 1-4) at concentrations of $50 \mathrm{nM}$ for each agent, and a washout phase of the 3DD cell culture system followed. The measured PD variables included cellular responses from the control (no treatment) and P(DE) treatment arms. Paclitaxel PK was described with a two-compartment mammillary model, whereas dasatinib and everolimus concentrations were simulated based on their dosing regimens and the input and output flow rates of media into the 3DD cell culture system (Supplemental Fig. 2).

The QSP model for intracellular signaling proteins was structurally identical to that of the $\mathrm{P}(\mathrm{DE})$ combination from the $2 \mathrm{D}$ setting (eqs. 57-84). To characterize JIMT-1 cell growth in the 3DD system, a hybrid model (Magni et al., 2006) comprising exponential and linear cell growth components was employed and modified to account for treatment effects. Before administration of DE $(<24$ hours), only paclitaxel action is accounted for as follows:

$$
\frac{d R}{d t}=\frac{\lambda_{0} \cdot R \cdot \mathrm{m}_{\mathrm{TOR}}{ }^{\alpha_{\mathrm{P}}}}{\left(1+\left(\frac{\lambda_{0}}{\lambda_{1}} \cdot R\right)^{\Psi}\right)^{\Psi}}-\beta_{\mathrm{P}} \cdot \triangle \mathrm{Cas} 3 \cdot R ; R(0)=R_{0}
$$

After 24 hours, the combined effect of $\mathrm{P}$ and DE is taken into account, as implemented in the $2 \mathrm{D}$ setting, as follows:

$$
\frac{d R}{d t}=\frac{\lambda_{0} \cdot R \cdot \mathrm{m}_{\mathrm{TOR}}{ }^{\alpha_{\mathrm{PDE}}}}{\left(1+\left(\frac{\lambda_{0}}{\lambda_{1}} \cdot R\right)^{\Psi}\right)^{\frac{1}{\Psi}}}-\beta_{\mathrm{PDE}} \cdot \triangle \mathrm{Cas} 3 \cdot R ; R(0)=R_{0}
$$

where $R$ is the number of tumor cells, $\lambda_{0}$ and $\lambda_{1}$ are rate constants describing the exponential and linear growth of JIMT-1 cells, $\Psi$ is a factor that allows for the switch from the exponential to the linear growth as tumor cell number increases, $\alpha_{\mathrm{P}}$ and $\alpha_{\mathrm{PDE}}$ are the power coefficients associated with effect of pmTOR protein activity on the inhibition of cell growth before and after 24 hours, and $\beta_{\mathrm{P}}$ and $\beta_{\mathrm{PDE}}$ are the death rate constants for JIMT-1 cells associated with caspase-3 protein activity before and after 24 hours. $\triangle$ Cas3 represents the change in caspase- 3 activity from its baseline and was used to drive the killing of JIMT-1 cells.

To translate JIMT-1 cells responses from the 2D to 3DD cell culture setting, the cell growth inhibition rate constants associated with pmTOR activity and the cell death rate constants associated with caspase-3 activity in both systems were compared, and their ratios were termed as "scaling factors." Moreover, comparison of the cell growth data between 2D and 3DD settings for the control (notreatment) arm indicated that the first-order growth rate constants in both systems were nearly identical, hence demonstrating a direct translatability of the JIMT-1 cellular response from the 2D to 3DD cell culture system for the control (no-treatment) arm.

The scaling factors $\left(\alpha_{\mathrm{P}} / k d_{\mathrm{P}}, \alpha_{\mathrm{PDE}} / k d_{\mathrm{PDE}}\right)$ and $\left(\beta_{\mathrm{P}} / k d_{\mathrm{P}}, \beta_{\mathrm{PDE}} / k d_{\mathrm{PDE}}\right)$ were calculated by using estimates from the model fittings for the $\mathrm{P}(\mathrm{DE})$ arm in the $3 \mathrm{DD}$ and $2 \mathrm{D}$ cell culture settings. These scaling factors were then used to determine cell growth inhibition and cell death coefficients for the other treatment arms in the 3DD system (using the parameter estimates obtained from their 2D-system models), which included everolimus and dasatinib as single agents and in combination; paclitaxel alone; and paclitaxel, dasatinib, and everolimus as a simultaneous combination (PDE). The calculated coefficients were used to simulate cellular response in the 3DD setting for the above treatment arms, and their simulated profiles were compared with the sequential treatment $(\mathrm{P}(\mathrm{DE}))$ arm model fitting.

The final QSP-PK/PD model from the 3DD cell culture system was used to simulate cellular responses under various treatment schedules that included interdose intervals of $24,48,72,96$, and 120 hours for the $\mathrm{P}(\mathrm{DE})$ sequential combination and $\mathrm{PDE}$ and $\mathrm{P}(\mathrm{DE})$ treatment combinations at half the concentration levels used for each agent (i.e., $25 \mathrm{nM}$ for 72 hours followed by washout). Additionally, long-term JIMT-1 cellular responses for all treatment arms were simulated (up to 50 days). To evaluate the relative efficacy and duration of response of these treatment schedules, the time-course profiles were compared for the time to JIMT-1 cells regrowth after cessation of treatment.

\section{Results}

The schematic representation of the mathematical model for the protein signaling networks and cellular response is depicted in Fig. 1.

\section{QSP Models for Protein Dynamics and Cellular Response in the 2D Cell Culture Setting}

Protein Dynamics. The protein signaling networks and their impact on JIMT-1 cellular responses were established based on knowledge of the mechanisms of action of each single agent and combinations, and on the pattern of time-course profiles of measured proteins expression from JIMT-1 cells exposed to the various treatments in the $2 \mathrm{D}$ cell-culture setting. The established protein network models were used 
to drive cell viability of JIMT-1 cells for all tested treatment arms.

A decline in pAkt and pmTOR expression levels was observed after treatment with paclitaxel, indicating a cell growth inhibitory effect, in addition to activation of caspase-3, leading to an apoptotic effect in JIMT-1 cells (Fig. 2). JIMT-1 cells treatment with dasatinib led to a decline in the expression level of its pharmacological target pSrc, and subsequently a decline in downstream pAkt and pmTOR expression levels (Fig. 2). Hence, pmTOR protein activity was used as the driver of the dasatinib inhibitory effect on JIMT-1 cell growth. For everolimus, a decline in pmTOR protein activity was observed in accordance with its mechanism of action, as represented in Fig. 2. Moreover, a feedback activation of pAkt was also observed in parallel, a phenomenon that is commonly observed in response to pmTOR inhibition in several tumor types through release of feedback inhibition from upstream tyrosine kinase signaling pathways (O'Reilly et al., 2006). In addition, we observed an increase in the expression levels of pSrc in response to everolimus treatment, which also contributed to an increase in pAkt protein expression and cell growth (Fig. 2). Notably, we did not observe any significant increase in caspase-3 activity for dasatinib or everolimus as single agents, indicating their cytostatic role in the HER2-therapy resistant JIMT-1 cell line.

Figure 3 depicts the temporal changes in the signaling protein levels compared with control for all examined combination therapies, including DE, PDE (simultaneous), and $\mathrm{P}(\mathrm{DE})$ (sequential). The dual and triple combination (DE, $\mathrm{PDE}$, and $\mathrm{P}(\mathrm{DE})$ ) model structures were built in a hierarchical manner by including components from the individual agents' model structures. For example, the DE model was an integration of the dasatinib and everolimus single-agent models with suppression of the pSrc feedback activation loop and attenuation of the pAkt feedback activation loop when the two drugs were administered simultaneously. For the P(DE) sequential model, components of the paclitaxel model were included at times earlier than 24 hours, while components of the PDE model were used at times beyond 24 hours when DE treatment was administered.

In the DE combination arm, both pharmacological targets for dasatinib (pSrc) and everolimus (pmTOR) declined over time. Similarly, a decline to levels below the initial baseline value of the pAkt protein was observed, confirming the hypothesis that dasatinib counterregulates the feedback activation loop of pAkt upon inhibition of pmTOR by everolimus.

In the DE-perturbed protein model, components of the dasatinib and everolimus single-agents' protein models were integrated and their parameters were fixed in the combination model to test their ability at capturing protein trends in the DE treatment arm. The only parameter that was estimated in this integrated model was the coefficient for effect of pAkt on pmTOR $\left(S 1_{\mathrm{DE}}\right)$, which was comparable with the corresponding coefficient in the everolimus single-agent model $\left(S 2_{\mathrm{E}}\right): 1.36 \pm$ 0.46 versus $1.42 \pm 0.11$ (Table 1 ). This parameter was estimated and compared with the everolimus arm because the two transit compartments describing the delay in effect on pmTOR due to pAkt in the dasatinib model $\left(K_{\mathrm{M} 1}\right.$ and $\left.K_{\mathrm{M} 2}\right)$ were eliminated in this model, as there was direct inhibition of pmTOR due to everolimus. Additionally, the feedback activation loop from pmTOR to pSrc was also eliminated in this model because the pSrc levels were comparable to the dasatinib single-agent arm (Figs. 2 and 3), indicating that dasatinib completely suppresses everolimus-mediated feedback activation of pSrc. The trends in protein dynamics for the DE arm were captured reasonably well, thus qualifying our dasatinib and everolimus single-agent models. Finally, a slight elevation in the activity of caspase-3 protein (apoptosis marker) was also observed in the DE dual treatment arm (Fig. 3), which contributed to cell death in our cell viability model, in conjunction with the growth inhibitory effect due to pmTOR.

The simultaneous (PDE) and sequential ( $\mathrm{P}(\mathrm{DE})$ ) combination treatment models invoked features of the single agents and DE dual therapy models. There was a decline in pSrc, pAkt, and pmTOR expression levels observed for both treatment arms, with distinct phases of protein signaling before and after 24 hours as reflected in our observed data and model fittings for the sequential treatment arm (Fig. 3). Moreover, active caspase-3 levels were elevated above baseline with a relatively larger magnitude as compared with the DE dual therapy $(\sim 1.5$ times $)$ and paclitaxel treatment alone $(\sim 1.2$ times) for both triple-agent combinations (Figs. 2 and 3). Additionally, in the PDE treatment arm, the onset of caspase3 activation was observed to be earlier ( 24 hours) in comparison with the $\mathrm{DE}$ and $\mathrm{P}(\mathrm{DE})$ treatment arms (48 hours; Fig. 3), due to the combined synergistic activity of all three agents simultaneously.

Cellular Response. The established models for protein networks were able to capture the observed data relatively well and were used as drivers to characterize JIMT-1 cell viability (cellular response) over time for the various treatment arms.

Figure 4 represents JIMT-1 cellular response to all treatment arms. For paclitaxel, almost $70 \%$ of cell killing from baseline was observed at 72 hours, indicating its significantly cytotoxic role in causing inhibition of cell growth and stimulation of cell death in JIMT-1 cells. A decline in the viability of JIMT-1 cells was observed in the dasatinib treatment arm as compared to the control arm as well. This was captured with an inhibitory effect of the pmTOR protein on cell growth through the model parameter $S 4_{\mathrm{D}}$ (eq. 22).

In contrast, JIMT-1 cell viability did not decline in the everolimus treatment arm as compared with control. This result suggests the existence of a feedback activation loop from pmTOR to pAkt via proteins of key cell survival and growth pathways (S6K, IGF-1R, PI3K, Src), which confers very weak sensitivity of JIMT-1 cells to everolimus.

For the DE treatment arm, we observed a higher magnitude of cell killing as compared with either agent alone, due to attenuation of the feedback activation loop of pAkt in the presence of this dual combination. However, $100 \%$ cell killing was not achieved, due to the predominantly cytostatic effect of this combination.

For both the triple combination arms (PDE and P(DE)), the cytotoxic effects reached $100 \%$ killing of JIMT-1 cells by 96 hours, indicating superior efficacy of the triple combination compared with the single-agent arms and to DE therapy. Not surprisingly, in the $\mathrm{P}(\mathrm{DE})$ arm, the $\mathrm{DE}$ treatment after paclitaxel administration led to a slight delay (of approximately 24 hours) in JIMT-1 cell death as compared with the PDE simultaneous treatment arm (Fig. 4).

The model parameters obtained from modeling all the observed data collected in the $2 \mathrm{D}$ cell culture setting are 
TABLE 1

Parameter estimates for protein network dynamics and cellular response models for JIMT-1 cells in the 2D and 3DD systems

\begin{tabular}{l}
\multicolumn{1}{c}{ Parameter (Unit) } \\
\hline \\
Turnover of measured signaling proteins \\
$\left(\mathrm{h}^{-1}\right)$ \\
$K_{\text {src }}$ \\
$K_{\text {Akt }}$ \\
$K_{\mathrm{mTOR}}$ \\
$K_{\text {cas }}$ \\
Paclitaxel model parameters: $2 \mathrm{D}$ system \\
$K_{\text {inh }}\left(\mathrm{h}^{-1}\right)$ \\
$I \mathrm{p}\left(\times 10^{-1} \mathrm{nM}^{-1}\right)$ \\
$\left(1 / \tau_{\mathrm{MP}}\right)\left(\times 10^{-1} \mathrm{~h}^{-1}\right)$ \\
$S 1_{\mathrm{P}}$ \\
$\left(1 / \tau_{\mathrm{CP}}\right)\left(\times 10^{-1} \mathrm{~h}^{-1}\right)$ \\
$k_{\mathrm{P}}\left(\mathrm{nM} \mathrm{M}^{-1}\right)$ \\
$S 2_{\mathrm{P}}$ \\
$S 3_{\mathrm{P}}$ \\
$S 4_{\mathrm{P}}$ \\
$k g\left(\times 10^{-1} \mathrm{~h}^{-1}\right)$ \\
$k d_{\mathrm{P}}\left(\mathrm{h}^{-1}\right)$ \\
Dasatinib model parameters: $2 \mathrm{D}$ system \\
$S 1_{\mathrm{D}}\left(\times 10^{-1} \mathrm{nM}^{-1}\right)$ \\
$S 2_{\mathrm{D}}$ \\
$\left(1 / \tau_{\mathrm{MD}}\right)\left(\times 10^{-1} \mathrm{~h}^{-1}\right)$ \\
$S 3_{\mathrm{D}}$ \\
$k g\left(\times 10^{-1} \mathrm{~h}^{-1}\right)$ \\
$S 4_{\mathrm{D}}$ \\
\end{tabular}

Everolimus model parameters: 2D system $S 1_{\mathrm{E}}\left(\times 10^{-1} \mathrm{nM}^{-1}\right)$

$S 22_{\mathrm{E}}$

$\left(1 / \tau_{\mathrm{SE}}\right)\left(\mathrm{h}^{-1}\right)$

$S 3_{\mathrm{E}}$

$S 4_{\mathrm{E}}$

$S 5_{\mathrm{E}}$

$k g\left(\times 10^{-1} \mathrm{~h}^{-1}\right)$

$S 6_{\mathrm{E}}$

Dasatinib + everolimus model parameters: $2 \mathrm{D}$ system

$S 1_{\mathrm{DE}}$

$\left(1 / \tau_{\mathrm{CDE}}\right)\left(\mathrm{h}^{-1}\right)$

$k_{\mathrm{DE}}\left(\mathrm{nM}^{-1}\right)$

$S 2_{\mathrm{DE}}$

$S 3_{\mathrm{DE}}\left(\times 10^{-1}\right)$

$k g\left(\mathrm{~h}^{-1}\right)$

$S 4_{\mathrm{DE}}$

$k d_{\mathrm{DE}}\left(\mathrm{h}^{-1}\right)$

Paclitaxel + dasatinib + everolimus

simultaneous treatment model

parameters: 2D system

$S 1_{\mathrm{PDE}}$

$S 2_{\mathrm{PDE}}$

$\left(1 / \tau_{\mathrm{CPDE}}\right)\left(\times 10^{-1} \mathrm{~h}^{-1}\right)$

$k g\left(\mathrm{~h}^{-1}\right)$

$S 33_{\mathrm{PDE}}$

$k d_{\mathrm{PDE}}\left(\times 10^{-1} \mathrm{~h}^{-1}\right)$

Paclitaxel + (dasatinib + everolimus $)$

sequential treatment model

parameters: 2D system

$\mathrm{S} 2_{\mathrm{P}(\mathrm{DE})}$

$\mathrm{S} 1_{\mathrm{P}(\mathrm{DE})}$

$\mathrm{kg}\left(\mathrm{h}^{-1}\right)$

$\mathrm{S} 44_{\mathrm{P}}$

$\mathrm{S} 33_{\mathrm{PDE}}$

$\operatorname{kd}_{\mathrm{P}}\left(\times 10^{-1} \mathrm{~h}^{-1}\right)$

$\operatorname{kd}_{\mathrm{PDE}}\left(\mathrm{h}^{-1}\right)$
Turnover rate constant for pSrc

0.237

Turnover rate constant for pAkt

Turnover rate constant for pmTOR

Turnover rate constant for active caspase-3

3.37

0.094

0.02

Turnover rate constant for pAkt inhibitory compartment

Coefficient of pAkt inhibition by paclitaxel

Transit rate constant for effect of pAkt on pmTOR due to paclitaxel

Coefficient of inhibition of pmTOR

Transit rate constant for activation of caspase-3 due to paclitaxel

Slope for activation of caspase-3

Exponent for activation of caspase-3

Feedback coefficient for active caspase-3

Coefficient of paclitaxel-mediated cell growth inhibition due to pmTOR

Net growth rate constant for JIMT-1 cells

Death rate constant for JIMT-1 cells due to paclitaxel

Estimate

Relative S.E (\% RSE)

Coefficient of pSrc inhibition by dasatinib

Coefficient of inhibition of pAkt due to pSrc

Transit rate constant for effect of pAkt on pmTOR due to dasatinib

Coefficient of inhibition of pmTOR

Net growth rate constant for JIMT-1 cells

Coefficient of dasatinib-mediated cell growth inhibition due to pmTOR

Coefficient of pmTOR inhibition by everolimus

Coefficient for effect of pAkt on pmTOR

Transit rate constant for feedback activation effect of pmTOR on pSrc

Coefficient of feedback activation of pSrc due to pmTOR

Coefficient of feedback activation of pAkt due to pmTOR

Coefficient of effect of pSrc on pAkt

Net growth rate constant for JIMT-1 cells

Coefficient of everolimus-mediated cell growth inhibition due to pmTOR

0.708

0.173

0.567

$1^{a}$

0.697

$1^{b}$

0.445

15.3

$1^{a}$

0.089

0.123

0.181

0.293

0.701

4.76

0.089

10.9

Coefficient for effect of pAkt on pmTOR

Transit rate constant for activation of caspase-3 due to dasatinib + everolimus $(\mathrm{D}+\mathrm{E})$

Slope for activation of caspase-3

Exponent for activation of caspase-3

Signal modulation coefficient for caspase-3 activation

Net growth rate constant for JIMT-1 cells

Coefficient of D+E-mediated cell growth inhibition due to pmTOR

Death rate constant for JIMT-1 cells due to D+E

0.151

1.42

1

7.27

$1^{a}$

0.089

$0.001^{c}$

1.36

0.996

Coefficient for effect of pAkt on pmTOR

Coefficient for feedback effect on pAkt due to pmTOR

Transit rate constant for activation of caspase-3 due to paclitaxel + dasatinib + everolimus $(\mathrm{P}+\mathrm{D}+\mathrm{E})$

Net growth rate constant for JIMT-1 cells

Coefficient of $\mathrm{P}+\mathrm{D}+\mathrm{E}-$ mediated cell growth inhibition due to pmTOR

Death rate constant for JIMT-1 cells due to $\mathrm{P}+\mathrm{D}+\mathrm{E}$

Coefficient for feedback effect on pAkt due to pmTOR

Coefficient for effect of pAkt on pmTOR

Net growth rate constant for JIMT-1 cells

Coefficient of paclitaxel-mediated cell growth inhibition due to pmTOR (before $24 \mathrm{~h}$ )

Coefficient of PDE mediated cell growth inhibition due to pmTOR (after $24 \mathrm{~h}$ )

Death rate constant for JIMT-1 cells due to paclitaxel (before $24 \mathrm{~h}$ )

Death rate constant for JIMT-1 cells due to PDE (after $24 \mathrm{~h}$ )

$\begin{array}{lr}0.0943 & 17 \\ 1.01 & 27 \\ 0.009 & 6 \\ 1^{a} & - \\ & \\ 1^{a} & - \\ & - \\ 0.774 & 4 \\ 0.124 & 10\end{array}$




\begin{tabular}{|c|c|c|c|}
\hline Parameter (Unit) & Definition & Estimate & $\begin{array}{c}\text { Relative S.E } \\
\quad(\% \text { RSE })\end{array}$ \\
\hline \multicolumn{4}{|c|}{$\begin{array}{l}\text { Paclitaxel }+(\text { dasatinib }+ \text { everolimus }) \\
\text { sequential treatment model } \\
\text { parameters: } 3 \mathrm{DD} \text { system }\end{array}$} \\
\hline$\lambda_{0}\left(\times 10^{-2} \mathrm{~h}^{-1}\right)$ & Rate constant for exponential growth of JIMT-1 cells & 0.77 & 5 \\
\hline$\lambda_{1}\left(\mathrm{~h}^{-1}\right)$ & Rate constant for linear growth of JIMT-1 cells & 7.41 & 59 \\
\hline$\Psi$ & Switching factor between exponential and linear growth & $20^{d}$ & - \\
\hline$\alpha_{\mathrm{P}}$ & Coefficient for JIMT-1 growth inhibition due to pmTOR (before $24 \mathrm{~h}$ ) & 1 & 23 \\
\hline$\beta_{\mathrm{P}}\left(\mathrm{h}^{-1}\right)$ & Death rate constant for JIMT-1 due to caspase- 3 activity (before $24 \mathrm{~h}$ ) & 0.132 & 3 \\
\hline$\alpha_{\mathrm{PDE}}$ & Coefficient for JIMT-1 growth inhibition due to pmTOR (after $24 \mathrm{~h}$ ) & 1 & 23 \\
\hline$\beta_{\mathrm{PDE}}\left(\times 10^{-1} \mathrm{~h}^{-1}\right)$ & Death rate constant for JIMT- 1 due to caspase- 3 activity (after $24 \mathrm{~h}$ ) & 0.841 & 3 \\
\hline \multicolumn{4}{|c|}{$\begin{array}{l}\text { Scaling factors for translation of } 2 \mathrm{D} \\
\text { models to the } 3 \mathrm{DD} \text { system }\end{array}$} \\
\hline$\alpha_{\mathrm{P}} / S 4_{\mathrm{P}}, \alpha_{\mathrm{PDE}} / S 2_{\mathrm{PDE}}$ & Ratio of cell growth inhibition coefficients in $3 \mathrm{DD}$ and $2 \mathrm{D}$ & 1 & - \\
\hline$\beta_{\mathrm{P}} / k d_{\mathrm{P}}, \beta_{\mathrm{PDE}} / k d_{\mathrm{PDE}}$ & Ratio of cell death rate constants in 3DD and 2D systems & 1.07 & - \\
\hline
\end{tabular}

${ }^{a}$ Coefficients were fixed to 1 to indicate a direct/inverse proportionality (as applicable) to the actual magnitude of the activity of a particular protein, without the need of a power coefficient.

${ }^{b}$ Slopes (proportionality constants) were fixed to 1 as the exponents used to characterize activation of caspase-3 due to drug concentrations alone were sufficient.

${ }^{c}$ Coefficient fixed to a relatively low magnitude to indicate minimal effect of activity of a protein. Any decrease in magnitude of this coefficient did not have an impact on model fittings.

${ }^{d}$ Fixed factor to allow for a smooth switch from exponential to linear cell growth (Magni et al., 2006).

summarized in Table 1. The parameters for all models (single and combination therapies) were estimated with reasonable precision. Certain parameters in the models were fixed to improve model stability. For example, coefficients for the effect of certain proteins on others were fixed to 1 , as direct/inverse proportionality (as applicable) was sufficient to characterize these effects. Fixing these parameters did not have any significant impact on model performance as it did not change parameter estimates, nor did it compromise the precision of the remaining estimated parameters. In the case of everolimus treatment, because it had practically no effect on JIMT-1 cell viability, the inhibitory coefficient for cell growth due to mTOR protein activity $\left(S 6_{\mathrm{E}}\right)$ was fixed to a very low value of 0.001 (Table 1), as identified from trial and error. No change in the effect on cell growth inhibition was observed at magnitudes lower than this. Overall, the established models could adequately capture the observed data, with reasonable precision on parameter estimates.

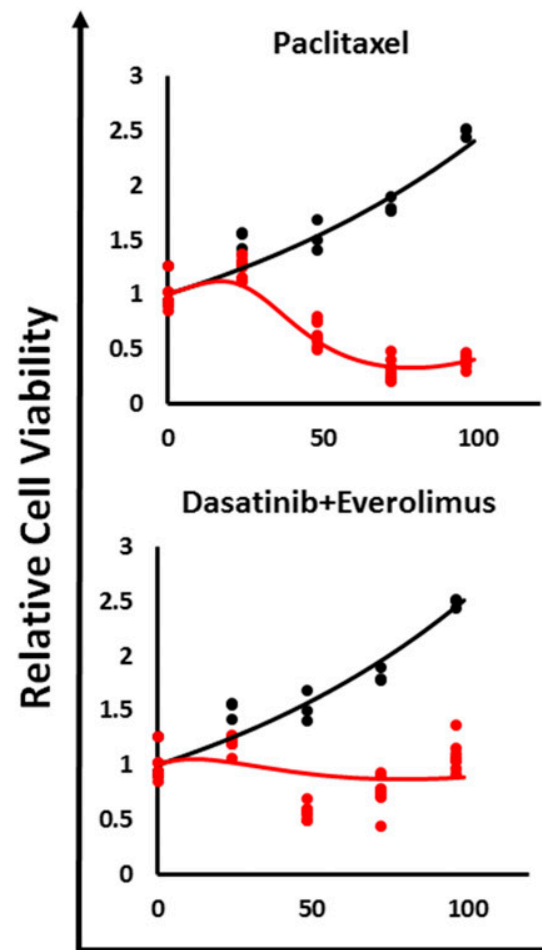

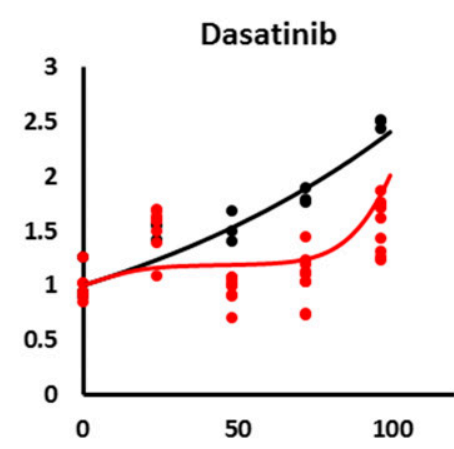

Paclitaxel+Dasatinib+Everolimus

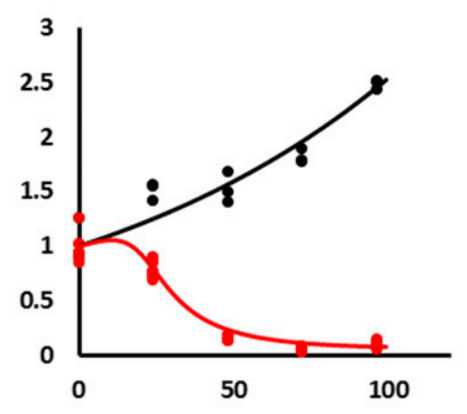

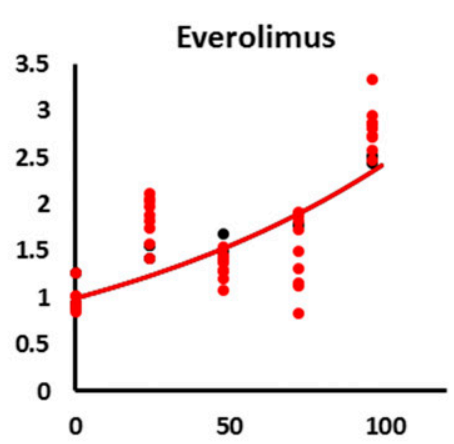

Paclitaxel $\rightarrow$ (Dasatinib+Everolimus)

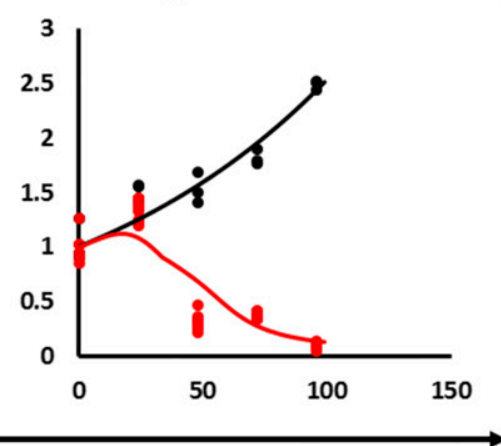

\section{Time (h)}

Fig. 4. Time course of cellular viability response after continuous exposure of JIMT-1 cells to treatments with paclitaxel (50 $\mathrm{nM}$ ), dasatinib (50 $\mathrm{nM}$ ), everolimus (50 nM), DE (50 nM each), PDE (50 nM each), and P(DE) (50 nM each). Black circles represent observed data under control conditions, and red circles represent observed data under treatment conditions. Solid lines represent model fittings. 


\section{QSP and PK/PD Models for Cellular Responses in the 3DD Cell Culture Setting}

Figure 5 depicts the time-course profiles of JIMT-1 cell viability in the 3DD cell culture setting for actual measurements and model fittings of control and $\mathrm{P}(\mathrm{DE})$ treatment arms, along with simulated response profiles for various dosing regimens of single and combination therapies. A hybrid exponential and linear cell growth model could adequately describe the growth of JIMT-1 cells in the absence of treatment in the 3DD system, whereas in a $2 \mathrm{D}$ cell culture setting, an exponential model was sufficient to characterize JIMT-1 cell growth. The rate constants for the exponential cell growth in 2D and 3DD settings were similar in magnitude and determined at 0.009 versus 0.008 hour $^{-1}$ in $2 \mathrm{D}$ versus $3 \mathrm{DD}$ (Table 1). This result supports at least in part the translatability of findings for JIMT-1 cells from a 2D to 3DD cell culture setting.

Furthermore, the time-course of JIMT- 1 cells viability in the 3DD cell culture system was reasonably captured for both treatment arms, control and sequential triple combination, using our established protein network model as a driver for JIMT-1 cellular response (black and red solid lines). The coefficients for inhibition of cell growth due to mTOR activity and stimulation of cell death due to caspase-3 activity in the 2D and 3DD systems for the sequential treatment arm (Table 1) were compared. The cell growth inhibition and cell death coefficients were not significantly different between the two settings (with ratios of 1 and 1.07, respectively), indicating translatability of our 2D QSP models to the 3DD system. These ratios were used as scaling factors to simulate the time-course profiles of JIMT-1 cells viability in the 3DD setting for the remaining treatment arms.

The dasatinib (green) and everolimus (blue) treatment arms demonstrated a marginal decrease in JIMT-1 cell viability from the control, mainly due to their cytostatic effects, whereas the DE treatment arm (orange) showed significantly higher cell killing than either agent alone. The simulated time-course profiles of JIMT-1 cell killing were more noticeable in the single-agent paclitaxel treatment arms when it was administered at a concentration regimen mimicking dasatinib and everolimus (50 $\mathrm{nM}$ for 72 hours followed by washout; yellow) and administered as per the 3DD experimental study design (3-hour short-term infusion; pink).

A comparison of the simulated response of JIMT-1 cells to PDE (purple dashed) and P(DE) (red dashed) treatments with all three drugs administered at the same dose levels $(50 \mathrm{nM}$ for 72 hours followed by washout) showed a comparable magnitude of cell killing ( $\sim 1.2$-fold greater maximum cell killing with the PDE simultaneous arm as compared with the P(DE) sequential arm), with a cell response approaching similar magnitudes at later time points (beyond $\sim 200$ hours). This was an expected finding as the sequential combination causes a delay in onset of JIMT-1 cell death due to dose staggering, as opposed to the simultaneous regimen with all three agents exerting cytostatic and/or cytotoxic effects through distinct mechanisms of action at the same time. A similar phenomenon was also observed in the 2D system (Fig. 4), thus corroborating our findings from the 3DD simulations and providing confidence in our scaled-up QSP-PK/PD model. Moreover, these results suggest potential for dose staggering of $\mathrm{P}$ and $\mathrm{DE}$ while achieving similar efficacy as that of the PDE simultaneous treatment arm in HER2-therapy resistant BC.

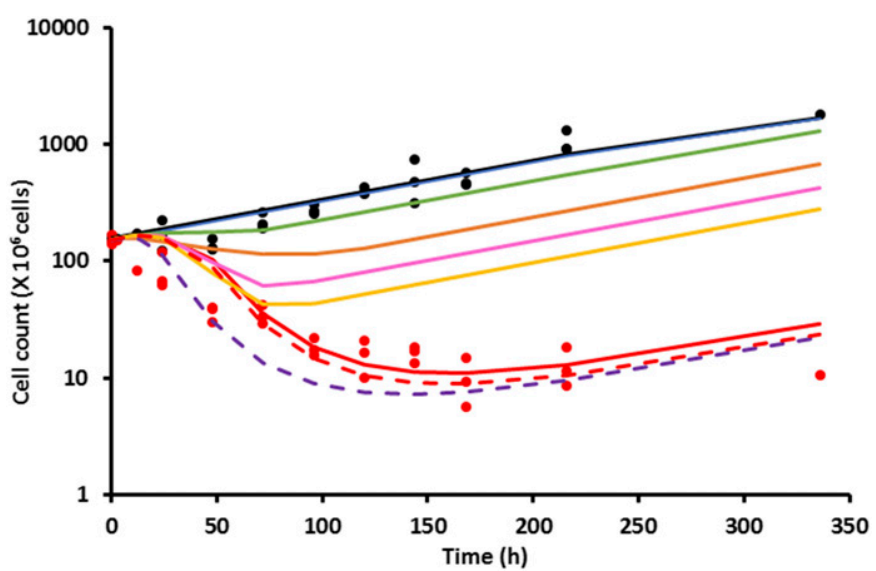

Fig. 5. Time course of cell viability response of JIMT-1 cells in the 3DD cell culture system. Black circles are observed data under control conditions, black solid profile is the model fitting for control data, red circles are observed data for $\mathrm{P}(\mathrm{DE})$ treatment arm in the 3DD study, red solid profile is the model fitting for the $\mathrm{P}(\mathrm{DE})$ treatment arm, blue profile is everolimus ( $50 \mathrm{nM}$ for 72 hours followed by washout), green profile is dasatinib (50 $\mathrm{nM}$ for 72 hours followed by washout), orange profile is DE ( $50 \mathrm{nM}$ for 72 hours followed by washout), pink profile is paclitaxel (3-hour short-term infusion followed by washout), yellow profile is paclitaxel (50 nM for 72 hours followed by washout), purple dashed profile is PDE ( $50 \mathrm{nM}$ for 72 hours followed by washout for all three agents administered simultaneously), red dashed profile is $\mathrm{P}(\mathrm{DE})$ (50 $\mathrm{nM}$ for 72 hours with a 24-hour interval between $\mathrm{P}$ and $\mathrm{DE}$, followed by washout).

Figure 6 depicts the simulated responses of JIMT-1 viability for various treatment schedules (Fig. 6A) and over a long-term treatment period of 50 days (Fig. 6B). The additional simulated treatment schedules included $\mathrm{P}(\mathrm{DE})$ sequential treatment with interdose intervals of $24,48,72,96$, and 120 hours, with all three drugs administered at the same dose levels (50 $\mathrm{nM}$ for 72 hours followed by washout), and PDE and P(DE) (24-hour interval) treatment combinations at half-dose levels ( $25 \mathrm{nM}$ for 72 hours followed by washout). A slight delay was observed in the time to tumor regrowth (TTR) of tumor cells in the $\mathrm{P}(\mathrm{DE})$ regimens for the intervals of 48 and 72 hours (Fig. $6 \mathrm{~A}$, green and yellow dashed profiles) as compared with the PDE simultaneous regimen (purple dashed profile) although the magnitude of tumor cell killing was comparable. Beyond interdose intervals of 72 hours, however, the $\mathrm{P}(\mathrm{DE})$ sequential treatment regimens were not as efficacious as the simultaneous PDE regimen (96-hour interval; blue dashed profile and 120-hour interval; orange dashed profile), indicating almost complete washout of paclitaxel before $\mathrm{DE}$ administration and thus minimizing overlapping synergistic effects of the three agents. Nonetheless, the TTR was significantly delayed as compared with paclitaxel or DE treatment alone. Notably, despite reduction in the dose levels by half, the PDE and $\mathrm{P}(\mathrm{DE})$ triple combinations had significantly higher efficacy in JIMT-1 cells as compared with the single- and dual-agent arms (black and gray dashed profiles).

Figure 6B represents simulated JIMT-1 cell growth profiles over a longer period of time (50 days), until all growth curves became nearly parallel to one another. The calculated TTR of tumor cells exposed to the various dosing regimens is summarized in Table 2. The individual agents dasatinib, everolimus, and paclitaxel and the dual-agent (DE) treatment arm had a relatively shorter TTR as compared with the PDE triple combination regimens. The $\mathrm{P}(\mathrm{DE})$ treatment arms with 48 and 72 hours interdose intervals showed the longest TTR 
without loss of efficacy as compared with the PDE treatment, suggesting a synergistic effect of all three agents in this time window. Moreover, a reduction in dose levels by half in the triple combinations yielded significantly higher efficacy in JIMT-1 cells as compared with the single agents, further corroborating the synergistic effect of these three drugs in overcoming resistance to HER2 and mTOR therapies in BC.

\section{Discussion}

HER2+ BC represents $25 \%$ of all BC cases and is associated with poor prognosis, high incidence of metastases, and low survival rates (Slamon et al., 1987; Burstein, 2005; Kennecke et al., 2010). Despite improved treatment outcomes with HER2-targeted therapies such as trastuzumab and lapatinib, innate and acquired resistance to therapy remains a major unmet medical need (Pohlmann et al., 2009; Arteaga et al., 2011; Zhang et al., 2017). Here, we propose the use of a triple combination therapy comprising two targeted small-molecule agents, dasatinib and everolimus, in combination with the standard cytotoxic agent paclitaxel to overcome resistance to HER2 therapy in HER2+ BC.

Dasatinib and everolimus are inhibitors of Src and mTOR, two key signaling proteins of the PI3K/Akt/mTOR pathway, downstream of several transmembrane tyrosine kinase receptors involved in cell growth and proliferation. The overactivation of Src and mTOR proteins has been implicated in nearly $50 \%$ of HER2+ BC cases (Yori et al., 2014). This medical challenge presents an opportunity for achieving enhanced cytostasis through dual inhibition of these proteins. Moreover, preclinical studies with HER2+ BC cell lines and animal models have showed the benefit of dual inhibition of Src and mTOR at intensifying cell-growth inhibition (Park et al., 2012; Yori et al., 2014). Taking into account the benefit of combining dasatinib and everolimus treatment of enhanced cell-growth inhibition, we also added a third agent to the combination, paclitaxel, as an inducer of apoptosis to augment the overall cytotoxic effect of our combination therapy.

In the present work, we tested the potential of our proposed triple combination therapy at overcoming resistance to HER2 therapy in the HER2-therapy resistant cell line JIMT-1. A combined experimental and computational QSP approach was successfully applied for control, single, and combination therapies, where temporal changes in molecular (protein signaling) and cellular responses were measured in 2D and 3DD cell culture systems and were successfully characterized with QSP models.

In the $2 \mathrm{D}$ in vitro setting, dasatinib as a single agent demonstrated a cytostatic effect through inhibition of the activity of Src protein followed by a decline in the Akt and mTOR protein activities, which led to inhibition of JIMT-1 cellular growth. Everolimus as a single agent, was inefficacious at inhibiting JIMT-1 cell growth at the concentrations tested, likely due to feedback activation of Src and Akt protein activities. Similar results have been previously reported on the weak sensitivity of JIMT-1 cells to everolimus (Dragowska et al., 2011). The combination of both agents successfully suppressed this feedback activation loop, leading to a much higher cytostatic effect than either agent alone. This was an expected finding because both agents target proteins in the aberrantly activated Akt/mTOR pathway in HER2-resistant $\mathrm{BC}$ cells through distinct mechanisms of action that are also

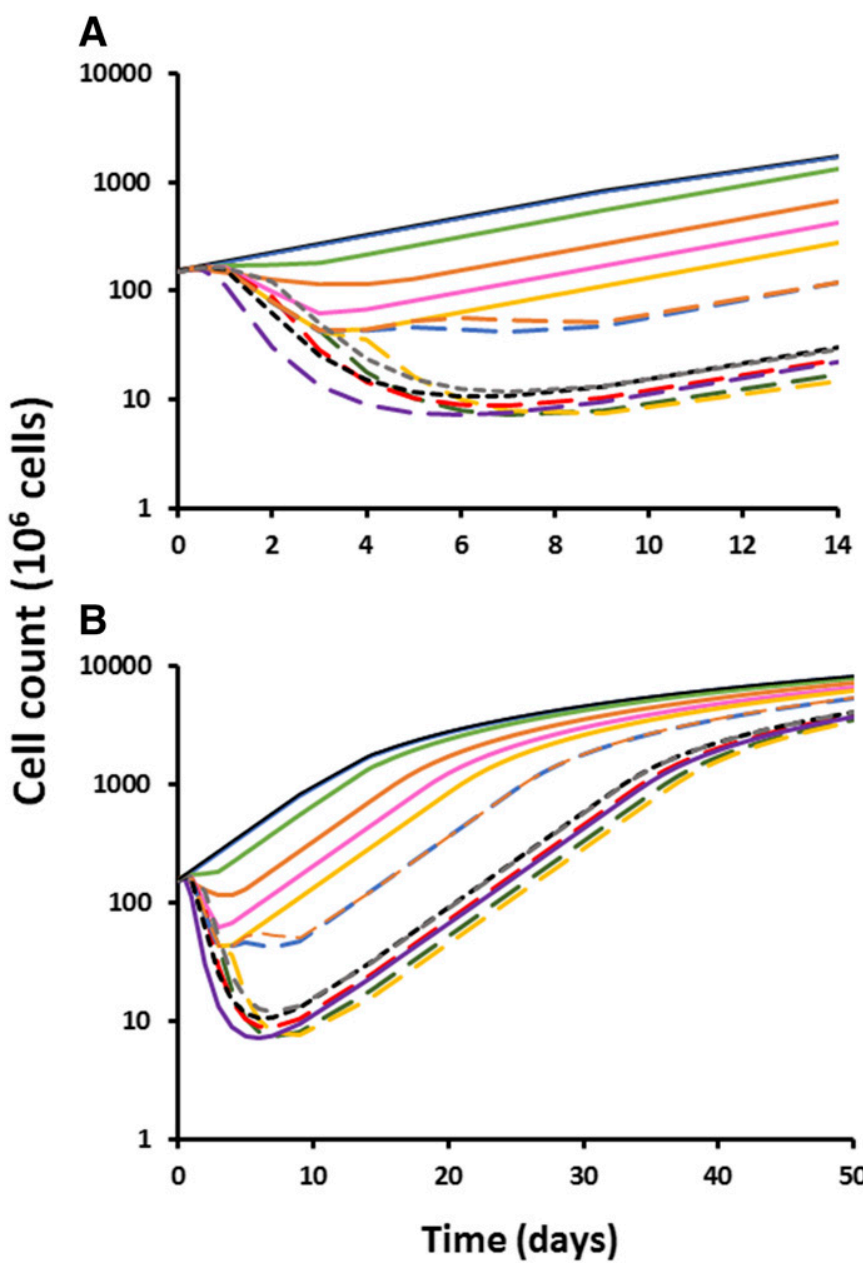

Fig. 6. Time course of cell viability response of JIMT-1 cells in 3DD cell culture system for (A) various treatment schedules and (B) simulations over a longer duration (50 days). The simulated dosing regimens are black profile: control arm, blue profile: everolimus (50 nM for 72 hours followed by washout); green profile: dasatinib (50 nM for 72 hours followed by washout); orange profile: $\mathrm{DE}$ (50 $\mathrm{nM}$ each for 72 hours followed by washout); pink profile: paclitaxel (3-hour short-term infusion); yellow profile: paclitaxel ( $50 \mathrm{nM}$ for 72 hours followed by washout); purple dashed profile: PDE (50 nM of each agent administered for 72 hours followed by washout); red dashed profile: $\mathrm{P}(\mathrm{DE})(50 \mathrm{nM}$ of each agent administered for 72 hours; 24-hour interval); green dashed profile: P(DE) (50 nM of each agent administered for 72 hours; 48-hour interval); yellow dashed profile: $\mathrm{P}(\mathrm{DE})$ (50 $\mathrm{nM}$ of each agent administered for 72 hours; 72-hour interval); blue dashed profile: $\mathrm{P}(\mathrm{DE})$ (50 $\mathrm{nM}$ of each agent administered for 72 hours; 96-hour interval); orange dashed profile: $\mathrm{P}(\mathrm{DE})$ (50 nM of each agent administered for 72 hours; 120 -hour interval); gray dashed profile: $\mathrm{P}(\mathrm{DE})$ ( $25 \mathrm{nM}$ of each agent administered for 72 hours; 24 -hour interval); black dashed profile: PDE ( $25 \mathrm{nM}$ of each agent administered for 72 hours simultaneously).

complementary to each other. Moreover, a study reported on other BC cell lines having feedback activation of Akt, yielded similar results upon treatment with a combination of dasatinib and rapamycin, an mTOR inhibitor (Yori et al., 2014).

The single agent paclitaxel showed both cytostatic and cytotoxic effects on JIMT-1 cells. This result is consistent with the mechanism of action of paclitaxel, causing microtubule disarray and cell cycle arrest followed by apoptosis (Horwitz, 1994; Wang et al., 2000). Furthermore, the cytostatic effect due to paclitaxel can also be attributed to inhibition of the central cellular signaling and growth protein Akt via dephosphorylation, as observed with our experimental data 
TABLE 2

Time to tumor regrowth (TTR) of JIMT-1 cells for dosing regimens simulated in the 3DD system The profile colors are found in Fig. 6B. The TTR was calculated as the horizontal distance between the control arm (black) and treatment profiles, when all growth curves became nearly parallel to one another after cessation of treatment.

\begin{tabular}{|c|c|c|}
\hline Dosing Regimen & Profile Color & TTR (d) \\
\hline \multicolumn{3}{|l|}{ Everolimus } \\
\hline $50 \mathrm{nM}$ for $72 \mathrm{~h}^{a}$ & Blue & - \\
\hline \multicolumn{3}{|l|}{ Dasatinib } \\
\hline $50 \mathrm{nM}$ for $72 \mathrm{~h}$ & Green & 2.2 \\
\hline \multicolumn{3}{|l|}{$\mathrm{DE}$} \\
\hline $50 \mathrm{nM}$ for $72 \mathrm{~h}$ & Orange & 6.1 \\
\hline \multicolumn{3}{|l|}{ Paclitaxel } \\
\hline 3-h short-term infusion & Pink & 8.6 \\
\hline $50 \mathrm{nM}$ for $72 \mathrm{~h}$ & Yellow & 10.9 \\
\hline \multicolumn{3}{|l|}{$\mathrm{P}(\mathrm{DE})$} \\
\hline Sequential, $120-\mathrm{h}$ interval; $50 \mathrm{nM}$ for $72 \mathrm{~h}$ & Orange dashed & 15.4 \\
\hline Sequential, 96 -h interval; $50 \mathrm{nM}$ for $72 \mathrm{~h}$ & Blue dashed & 15.5 \\
\hline Sequential, 24-h interval; $50 \mathrm{nM}$ for $72 \mathrm{~h}$ & Red dashed & 24.3 \\
\hline Sequential, 48 -h interval; $50 \mathrm{nM}$ for $72 \mathrm{~h}$ & Green dashed & 26.0 \\
\hline Sequential, 72 -h interval; $50 \mathrm{nM}$ for $72 \mathrm{~h}$ & Yellow dashed & 26.8 \\
\hline Sequential, 24-h interval; $25 \mathrm{nM}$ for $72 \mathrm{~h}$ & Gray dashed & 23.1 \\
\hline \multicolumn{3}{|l|}{ PDE } \\
\hline Simultaneous, $50 \mathrm{nM}$ for $72 \mathrm{~h}$ & Purple dashed & 24.6 \\
\hline Simultaneous, $25 \mathrm{nM}$ for $72 \mathrm{~h}$ & Black dashed & 22.9 \\
\hline
\end{tabular}

(Fig. 2) and in accordance with literature findings (MacKeigan et al., 2002; Sunters et al., 2006).

In the $2 \mathrm{D}$ setting, both triple combinations PDE (simultaneous) and $\mathrm{P}(\mathrm{DE})$ (sequential) showed strong cytotoxic effects on JIMT-1 cells, reaching $100 \%$ cell killing at 96 hours. Despite these comparable cytotoxicity effects of PDE and $\mathrm{P}(\mathrm{DE})$, only $\mathrm{P}(\mathrm{DE})$ was further examined in our novel 3DD cell culture system (Ande et al., 2018). The rationale was 2 -fold. First, prior treatment with paclitaxel is hypothesized to be particularly useful in the in vivo and/or clinical setting due to its tumor priming effect, through which it allows penetration of targeted agents and nanomedicines into the inner layers of solid tumors (Lu et al., 2007). Second, dose staggering of paclitaxel and the DE combination may provide a clinical safety benefit by reducing the occurrence and/or intensity of potential common adverse events of these drugs, particularly hematologic toxicities such as neutropenia and thrombocytopenia (Fornier et al., 2011; Ocana et al., 2017; Toi et al., 2017).

Our experimental results in the 3DD cell culture system showed that $\mathrm{P}(\mathrm{DE})$ treatment substantially blocked (8.5-fold compared with control) the growth of JIMT- 1 cells in a durable manner lasting beyond cessation of therapy (up to 15 days). The latter result would not be possible to obtain from a $2 \mathrm{D}$ cell culture experiment due to the relatively short maximum duration of study design ( $\sim 5$ days) in this setting. Hence, our novel $3 \mathrm{DD}$ cell culture system presents several advantages over the traditional 2D cell culture system. First, it allows serial sampling of cells over a relatively long period of time (2 or more weeks) for measurement of cellular response without significant perturbations in the system. Second, the system provides a three-dimensional environment for the growth of adherent cells, which is closer to an in vivo tumor environment than a standard $2 \mathrm{D}$ cell culture system. Third, it permits flexibility in adjusting the drugs' dosing regimens to mimic animal or human PK of drugs. This was used in our 3DD experiments where the PK of paclitaxel was simulated along with a constant exposure to DE combination therapy.
The subsequently measured PK and JIMT-1 cellular responses were well characterized with our scaled up QSPPK/PD model.

The calculated scaling factors (from 2D to 3DD) and the initial JIMT-1 growth rate constants indicated similarities between both systems and supported translation and applicability of our QSP models from the 2D setting to the 3DD setting. Our simulations of the simultaneous (PDE) and sequential $(\mathrm{P}(\mathrm{DE}))$ triple combinations (interdose intervals: 24,48 , and 72 hours) in the 3DD setting demonstrated similar magnitudes of cytotoxic effects, albeit with a slight delay in the onset of tumor cells regrowth for the $\mathrm{P}(\mathrm{DE})$ treatment as predicted by our long-term model simulations, thus providing an opportunity for dose staggering of $\mathrm{P}$ and $\mathrm{DE}$. Moreover, despite dose reduction of the triple combinations, significant efficacy against JIMT-1 cells was retained, as suggested by our model simulations, corroborating the synergistic effect of all three agents. The synergism can be largely attributed to DE-mediated targeted inhibition of the crucial PI3K/Akt/mTOR axis, which is aberrantly activated in HER2-therapy resistant BC, making the cells particularly susceptible to this treatment combination. Furthermore, this can provide opportunities to reduce individual dose levels for all three agents when used in combination, minimizing potential occurrence of overlapping side effects.

In summary, the superior efficacy of our proposed triple combination therapy of paclitaxel with dasatinib and everolimus at overcoming resistance to HER2-targeted therapies in BC is established in vitro. Our novel 3DD cell culture system allowed us to mimic the PK of the three agents, which influenced the dynamic changes in protein signaling and cellular responses of JIMT-1 cells. The final established QSP-PK/PD models were able to characterize cell viability in the 3DD system relatively well under the given treatment conditions, and were able to predict cellular responses to various other dosing regimens over a relatively long period of time. Thus, our approach of combining the use of our novel 
3DD cell culture system with the aid of QSP-PK/PD as a mathematical modeling and simulation tool has potential application for the screening of successful combination therapies in oncology and may serve as a surrogate for animal studies that may not be feasible in some cases and/or might not be representative of human systems.

\section{Acknowledgments}

The authors would like to acknowledge Ashley N. Brown and Michael Vicchiarelli (Department of Medicine, Institute for Therapeutic Innovation, University of Florida, Orlando) and Bao N. Tran for technical assistance.

\section{Authorship Contributions}

Participated in research design: Vaidya, Ande, Ait-Oudhia.

Conducted experiments: Ande.

Contributed new reagents or analytic tools: Vaidya, Ande, AitOudhia.

Performed data analysis: Vaidya, Ande, Ait-Oudhia.

Wrote or contributed to the writing of the manuscript: Vaidya, Ande, Ait-Oudhia.

\section{References}

Ande A, Vaidya TR, Tran BN, Vicchiarelli M, Brown AN, and Ait-Oudhia S (2018) Utility of a novel three-dimensional and dynamic (3DD) cell culture system for PK/PD studies: evaluation of a triple combination therapy at overcoming antiHER2 treatment resistance in breast cancer. Front Pharmacol 9:403.

Araujo J and Logothetis C (2010) Dasatinib: a potent SRC inhibitor in clinical development for the treatment of solid tumors. Cancer Treat Rev 36:492-500.

Arteaga CL, Sliwkowski MX, Osborne CK, Perez EA, Puglisi F, and Gianni L (2011) Treatment of HER2-positive breast cancer: current status and future perspectives. Nat Rev Clin Oncol 9:16-32.

Burstein HJ (2005) The distinctive nature of HER2-positive breast cancers. $N$ Engl J Med 353:1652-1654.

Chang AY and Wang M (2013) Molecular mechanisms of action and potential biomarkers of growth inhibition of dasatinib (BMS-354825) on hepatocellular carcinoma cells. BMC Cancer 13:267.

Chaturvedi D, Gao X, Cohen MS, Taunton J, and Patel TB (2009) Rapamycin induces transactivation of the EGFR and increases cell survival. Oncogene 28:1187-1196.

Chudasama VL, Ovacik MA, Abernethy DR, and Mager DE (2015) Logic-based and cellular pharmacodynamic modeling of bortezomib responses in U266 human myeloma cells. J Pharmacol Exp Ther 354:448-458.

Dehm SM and Bonham K (2004) SRC gene expression in human cancer: the role of transcriptional activation. Biochem Cell Biol 82:263-274.

De Luca A, D’Alessio A, Gallo M, Maiello MR, Bode AM, and Normanno N (2014) Src and CXCR4 are involved in the invasiveness of breast cancer cells with acquired resistance to lapatinib. Cell Cycle 13:148-156.

Dragowska WH, Weppler SA, Qadir MA, Wong LY, Franssen Y, Baker JH, Kapanen AI, Kierkels GJ, Masin D, Minchinton AI, et al. (2011) The combination of gefitinib and RAD001 inhibits growth of HER2 overexpressing breast cancer cells and tumors irrespective of trastuzumab sensitivity. BMC Cancer 11:420.

Fornier MN, Morris PG, Abbruzzi A, D’Andrea G, Gilewski T, Bromberg J, Dang C, Dickler M, Modi S, Seidman AD, et al. (2011) A phase I study of dasatinib and weekly paclitaxel for metastatic breast cancer. Ann Oncol 22:2575-2581.

Haltia UM, Andersson N, Yadav B, Färkkilä A, Kulesskiy E, Kankainen M, Tang J, Bützow R, Riska A, Leminen A, et al. (2017) Systematic drug sensitivity testing reveals synergistic growth inhibition by dasatinib or mTOR inhibitors with paclitaxel in ovarian granulosa cell tumor cells. Gynecol Oncol 144:621-630.

Ho L, Greene CL, Schmidt AW, and Huang LH (2004) Cultivation of HEK 293 cell line and production of a member of the superfamily of G-protein coupled receptors for drug discovery applications using a highly efficient novel bioreactor. Cytotechnology 45:117-123.

Horwitz SB (1994) Taxol (paclitaxel): mechanisms of action. Ann Oncol 5 (Suppl 6): S3-S6.

Houghton PJ (2010) Everolimus. Clin Cancer Res 16:1368-1372.

Jin MH, Nam AR, Park JE, Bang JH, Bang YJ, and Oh DY (2017) Resistance mechanism against trastuzumab in HER2-positive cancer cells and its negation by Src inhibition. Mol Cancer Ther 16:1145-1154.

Kennecke H, Yerushalmi R, Woods R, Cheang MC, Voduc D, Speers CH, Nielsen TO, and Gelmon K (2010) Metastatic behavior of breast cancer subtypes. J Clin Onco 28:3271-3277.

Köninki K, Barok M, Tanner M, Staff S, Pitkänen J, Hemmilä P, Ilvesaro J, and Isola $\mathrm{J}$ (2010) Multiple molecular mechanisms underlying trastuzumab and lapatinib resistance in JIMT-1 breast cancer cells. Cancer Lett 294:211-219.
Liao Y and Hung MC (2010) Physiological regulation of Akt activity and stability. Am $J$ Transl Res 2:19-42.

Lobo ED and Balthasar JP (2002) Pharmacodynamic modeling of chemotherapeutic effects: application of a transit compartment model to characterize methotrexate effects in vitro. AAPS PharmSci 4:E42.

Loibl S and Gianni L (2017) HER2-positive breast cancer. Lancet 389:2415-2429.

Lu D, Wientjes MG, Lu Z, and Au JL (2007) Tumor priming enhances delivery and efficacy of nanomedicines. J Pharmacol Exp Ther 322:80-88.

MacKeigan JP, Taxman DJ, Hunter D, Earp HS III, Graves LM, and Ting JP (2002) Inactivation of the antiapoptotic phosphatidylinositol 3-kinase-Akt pathway by the combined treatment of taxol and mitogen-activated protein kinase kinase inhibition. Clin Cancer Res 8:2091-2099.

Mager DE and Jusko WJ (2001) Pharmacodynamic modeling of time-dependent transduction systems. Clin Pharmacol Ther 70:210-216.

Magni P, Simeoni M, Poggesi I, Rocchetti M, and De Nicolao G (2006) A mathematical model to study the effects of drugs administration on tumor growth dynamics. Math Biosci 200:127-151.

O’Brien NA, McDonald K, Tong L, von Euw E, Kalous O, Conklin D, Hurvitz SA, di Tomaso E, Schnell C, Linnartz R, et al. (2014) Targeting PI3K/mTOR overcomes resistance to HER2-targeted therapy independent of feedback activation of AKT. Clin Cancer Res 20:3507-3520.

Ocana A, Gil-Martin M, Martín M, Rojo F, Antolín S, Guerrero Á, Trigo JM, Muñoz M, Pandiella A, Diego NG, et al. (2017) A phase I study of the SRC kinase inhibitor dasatinib with trastuzumab and paclitaxel as first line therapy for patients with HER2-overexpressing advanced breast cancer. GEICAM/2010-04 study. Oncotarget 8:73144-73153.

O'Reilly KE, Rojo F, She QB, Solit D, Mills GB, Smith D, Lane H, Hofmann F, Hicklin DJ, Ludwig DL, et al. (2006) mTOR inhibition induces upstream receptor tyrosine kinase signaling and activates Akt. Cancer Res 66:1500-1508.

Park BJ, Whichard ZL, and Corey SJ (2012) Dasatinib synergizes with both cytotoxic and signal transduction inhibitors in heterogeneous breast cancer cell lines-lessons for design of combination targeted therapy. Cancer Lett $\mathbf{3 2 0}$ 104-110.

Pohlmann PR, Mayer IA, and Mernaugh R (2009) Resistance to trastuzumab in breast cancer. Clin Cancer Res 15:7479-7491.

Sharma A, Ebling WF, and Jusko WJ (1998) Precursor-dependent indirect pharmacodynamic response model for tolerance and rebound phenomena. J Pharm Sci 87: 1577-1584.

Singh JC, Jhaveri K, and Esteva FJ (2014) HER2-positive advanced breast cancer: optimizing patient outcomes and opportunities for drug development. $\mathrm{Br} J$ Cancer 111:1888-1898.

Slamon DJ, Clark GM, Wong SG, Levin WJ, Ullrich A, and McGuire WL (1987) Human breast cancer: correlation of relapse and survival with amplification of the HER-2/neu oncogene. Science 235:177-182.

Sun YN and Jusko WJ (1998) Transit compartments versus gamma distribution function to model signal transduction processes in pharmacodynamics. J Pharm Sci 87:732-737.

Sunters A, Madureira PA, Pomeranz KM, Aubert M, Brosens JJ, Cook SJ, Burgering BM, Coombes RC, and Lam EW (2006) Paclitaxel-induced nuclear translocation of FOXO3a in breast cancer cells is mediated by c-Jun NH2-terminal kinase and Akt. Cancer Res 66:212-220.

Toi M, Shao Z, Hurvitz S, Tseng LM, Zhang Q, Shen K, Liu D, Feng J, Xu B, Wang X, et al. (2017) Efficacy and safety of everolimus in combination with trastuzumab and paclitaxel in Asian patients with HER2+ advanced breast cancer in BOLERO1. Breast Cancer Res 19:47.

Toriniwa H and Komiya T (2007) Japanese encephalitis virus production in Vero cells with serum-free medium using a novel oscillating bioreactor. Biologicals 35: $221-226$.

Vaidya T, Kamta J, Chaar M, Ande A, and Ait-Oudhia S (2018) Systems pharmacological analysis of mitochondrial cardiotoxicity induced by selected tyrosine kinase inhibitors. J Pharmacokinet Pharmacodyn 45:401-418.

Wang TH, Wang HS, and Soong YK (2000) Paclitaxel-induced cell death: where the cell cycle and apoptosis come together. Cancer 88:2619-2628.

Wilks ST (2015) Potential of overcoming resistance to HER2-targeted therapies through the PI3K/Akt/mTOR pathway. Breast 24:548-555.

Yarden Y (2001) Biology of HER2 and its importance in breast cancer. Oncology 61 (Suppl 2):1-13.

Yori JL, Lozada KL, Seachrist DD, Mosley JD, Abdul-Karim FW, Booth CN, Flask $\mathrm{CA}$, and Keri RA (2014) Combined SFK/mTOR inhibition prevents rapamycininduced feedback activation of AKT and elicits efficient tumor regression. Cancer Res 74:4762-4771.

Zhang L, Huang Y, Zhuo W, Zhu Y, Zhu B, and Chen Z (2017) Identification and characterization of biomarkers and their functions for lapatinib-resistant breast cancer. Med Oncol 34:89.

Address correspondence to: Dr. Sihem Ait-Oudhia, Center for Pharmacometrics and Systems Pharmacology, Department of Pharmaceutics, College of Pharmacy, University of Florida, 6550 Sanger Road, Office \#469, Orlando, FL 32827. E-mail: sihem.bihorel@cop.ufl.edu 